\title{
A local scale analysis of manganese nodules influence on the Clarion-Clipperton Fracture Zone macrobenthos
}

\author{
Francesca Pasotti ${ }^{1,}{ }^{*}$, Mevenkamp Lisa ${ }^{1}$, Pape Ellen ${ }^{1}$, Błażewicz Magdalena ${ }^{3}$, Bonifácio Paulo ${ }^{4}$, \\ Riehl Torben ${ }^{5}$, De Smet Bart ${ }^{2}$, Lefaible Nene ${ }^{1}$, Lins Lidia ${ }^{1}$, Vanreusel Ann ${ }^{1}$
}

\author{
${ }^{1}$ Marine Biology Laboratory, Ghent University, Ghent, Belgium \\ 2 Flanders Marine Institute, Oostende, Belgium \\ ${ }^{3}$ Department of Polar Biology and Oceanobiology, University of Łódź, Łódź, Poland \\ 4 Ifremer, Centre Bretagne, REM EEP, Laboratoire Environnement Profond, ZI de la Pointe du 5 Diable, \\ CS 10070, F-29280, Plouzan, France \\ ${ }^{5}$ Biocenter Grindel \& Zoological Museum, University of Hamburg, Hamburg, Germany \\ * Corresponding author : Pasotti Francesca, email address : francesca.pasotti@ugent.be
}

\begin{abstract}
:
The present investigation focuses on the Global Sea Mineral Resources contract area B4S03 site in the Clarion-Clipperton Fracture Zone nodule fields. We investigated the sedimentary characteristics and the higher-taxon (order/class) and lower-taxon (family, morphospecies) diversity of the soft sediment macrobenthos with special focus on the dominant taxa (Isopoda, Polychaeta, Tanaidacea) in relation to nodule abundance. Across all analyses no consistent and/or significant differences between the two nodule-rich and the nodule free stations were found in terms of abiotic or biotic factors, suggesting that both habitat-types have similar sedimentary conditions and that macrofauna is represented by comparable densities and higher-taxon diversity across stations. Rarefaction/accumulation curves and sample coverage analysis shows that the current sampling effort was insufficient to characterize the B4S03 site diversity at morphospecies level but covered $>90 \%$ of the diversity at the family level for the three dominant taxa. The high number of singletons encountered, the patchiness and low densities of the investigated taxa coupled to the logistically limited potential for replication per habitat/station, may point to under-sampling bias of the current study with the risk to underestimate species diversity and overestimate endemism. We recommend a more extensive sampling with the combination of molecular tools coupled with taxonomical expertise.
\end{abstract}

\section{Highlights}

- GSR B4S03 nodule-rich and nodule-free stations are characterized by similar sedimentary parameters. - The nodule-rich stations showed comparable macrofauna densities but higher-taxon diversity to that of the nodule-free station. The sampling effort was insufficient to characterize the dominant taxa's diversity at morphospecies level. When the family level is considered $>90 \%$ of the diversity was sampled during this study. The high number of singletons, the patchiness and low densities may lead to an underestimation of species diversity. The high number of singletons, the patchiness and low densities may lead to an overestimation of endemism. 
Recent studies indicated that significant metals and rare earth elements resources - needed for the manufacturing of increasing numbers of high-tech products and green technologies for decarbonisation - are stored at the bottom of the oceans in the form of deep-sea mud and ferromanganese crusts, whereas rare metals (e.g., nickel, copper, cobalt and manganese) are found in polymetallic nodules (Burns and Burns, 1977; Petersen et al., 2016; Balaram, 2019). Polymetallic nodules were first discovered in the Kara Sea (Arctic Ocean) during the Challenger expedition in 1870 (Murray and Renard, 1891). These nodules form at depths ranging from 4000 to $6000 \mathrm{~m}$ on the oceans' abyssal plains through processes of mineral precipitation over millions of years. The Clarion-Clipperton Fracture Zone (CCFZ) extends for 6 million $\mathrm{km}^{2}$ in between the Clarion and Clipperton fractures, off the west coast of Mexico in the North-East Pacific. This region has been estimated to be the largest deep-sea polymetallic nodule reserve in the world (Peterson et al., 2016) and it has been since 1997 at the centre of the International Seabed Authority (United Nations) plans of work for exploration.

The deep sea harbours some of the most understudied ecosystems of our Planet where organisms have adapted to particular environmental conditions such as high pressure and low food availability (Smith et al., 2017). Renowned for its high biodiversity and low densities (Glover and Smith, 2003; Smith et al., 2008a; Rex and Etter, 2010), the deep sea hosts a large number of undescribed species (Bonifácio and Menot, 2019) as well as phylogenetic lineages represented nowhere else (Riehl et al., 2014; Christodoulou et al., 2019), and nodule fields are no exception (Amon et al., 2016; Bonifácio and Menot, 2019; Błażewicz et al., 2019; Gheerardyn and George, 2019; Jakiel et al., 2019; Wiklund et al., 2019). Since the 1970s an increasing number of expeditions took place with the common goal to estimate the biodiversity of the CCFZ nodule fields' macrobenthic communities. These investigations reported a generally unanticipated high and clearly under-sampled biodiversity which appeared to be directly related to the taxa abundance (the higher the abundance, the higher the diversity of a taxon) and its relationship to the longitudinal surface water productivity gradient in the area (Smith et al., 1996, 1997; Smith and Demopoulos, 2003; Smith et al., 2008a; Amon et al., 2016, 2017; Dover et al., 2017; Bonifácio and Menot, 2019). Further, other studies have indicated that the presence of polymetallic nodules on otherwise "de- 
sert-like" abyssal landscapes, influences the diversity, composition, distribution and abundance of meio-, macro- and megafauna in the region (Veillette et al., 2007a; Smith et al., 2008a; Amon et al., 2016; Vanreusel et al., 2016; De Smet et al., 2017). The surface of the nodules may act as anchorage substrate for sessile filter feeder species (such as alcyonaceans and antipatharian corals), thousand-years-old glass sponges and the associated interspecies assemblages (e.g. ophiuroids living on stalked sponges) which are otherwise virtually absent in the surrounding nodule-void sediments (Vanreusel et al., 2016; Kersken et al., 2019). Veillette et al., (2007a, 2007b) found that both at a regional and at the nodule facies scale, the texture and the extent of the exposed surface of these ferromanganese accretions displayed a structuring effect on the distribution and diversity of encrusting Foraminifera. Finally, the internal structure of the nodules seems to host specific crevice fauna, which differs in diversity and composition from that found outside the nodules (Pape et al., In prep.; Bussau, 1993; Thiel et al., 1993; Maybury, 1996; Veillette et al., 2007b, 2007a) Depending on management practices applied both during and after the nodule harvesting process, these functional groups may be lost from the exploited area without viable routes and substrates for recolonization.

The present analysis focuses on the soft sediment macrobenthos of the Global Sea Mineral Resources (GSR, Belgium) contract area and aims at providing new baseline information on the local-scale diversity patterns of soft sediment macrobenthic communities in relation to nodule abundance. We investigated the higher-taxon (order/class) macrofaunal assemblage structure and the lower-taxon (family, morphospecies) diversity of the three most abundant taxa (Isopoda, Polychaeta, Tanaidacea) by comparing two nodule-rich and one nodule-free habitat within one site (B4S03) in the GSR contract area. Furthermore, we present a list of identified morphospecies belonging to the three most dominant taxa and provide an estimation of the sampling effort necessary to observe different proportions of the estimated asymptotic diversity for the investigated B4S03 site. We hypothesize that the two nodule-rich stations investigated within this study will be similar in terms of higher-taxon and main taxa species/family composition of the whole assemblage, while differing from the nodule-free station. We also hypothesize a higher heterogeneity in environmental characteristics at the two nodule-rich stations with overall no differences in sedimentary feature among the three stations. Due to the local scale of this study (stations are located within a range of $2-10 \mathrm{~km}$ ) and building on the relationship between benthic abundances and the regional 
trends in the eupohotic zone productivity (Smith et al., 2008), we, moreover, do not expect differences in the total macrobenthic abundances between the three investigated stations.

\section{Material and Methods}

\subsection{Study area and sampling design}

The GSR contract area is comprised of three separate zones (B2, B6 and B4; Figure 1) located along a west to east direction within the CCFZ in the North-East Pacific Ocean. Based on the spatial heterogeneity in hydrodynamic features ultimately controlling primary productivity in the oceanic Eastern-Tropical Pacific, Pennington et al. (2006) delineated seven biogeographical provinces. Most of the GSR concession area falls within the North Equatorial Current (NEC) province $\left(13-23^{\circ} \mathrm{N}, 110 / 115-140^{\circ} \mathrm{W}\right)$. Within zone B4, the site B4S03 $(10 \times 20 \mathrm{~km})$ is located in between $14.13^{\circ} \mathrm{N}-14.0^{\circ} \mathrm{N}$ and $125.95^{\circ} \mathrm{W}-125.85^{\circ} \mathrm{W}$. As part of the commitment of GSR to follow the International Seabed Authority Recommendations (ISBA/25/LTC/6) provided for the Environmental Impact Assessment of future mining activities in the contract areas, we identified within the GSR B4S03 site a group of stations with high abundance of nodules and one site which is virtually nodule-free to investigate the soft sediment macrobenthic assemblages.

This study is based on samples collected during the GSRNOD17 expedition, which took place on board of the RV 'Topaz Captain' during May-June 2017. During the cruise two nodule-rich (Nodrich_A and Nodrich_B) and one nodule-free (Nodfree) stations were sampled (Figure 1). Nodule presence/absence at the sampling sites was established by means of multibeam echosounder (MBES) backscatter intensity data and AUV seabed photographs gathered during the preceding GSR cruise (GSRNOD15A; Pape et al., 2016; Juan et al., 2018) and verified by nodule abundance data from box-corer samples. Nodrich_B and Nodfree stations were located within an area of about $5 \times 5 \mathrm{~km}$ in the south-west of the B4S03, with Nodfree situated 2.6 $\mathrm{km}$ north from Nodrich_B. Nodrich_A was located in the north-east of B4S03 at a distance of about 7-10 km from the southern stations (see map in Figure 1). Within each station, a series of multiple-corer (MUC, MC800 series Ocean instruments, Inc.) and box-corer (BC, model BX-650, Ocean Instruments, Inc.) deployments were performed to sample the sediment environmental parameters (MUC) and to collect the macrofauna (BC, see supplementary table ST1). To cover the spatial heterogeneity of the area, the deployments were conducted a few hundreds of meters apart from each other (see location of BC on map Figure 1). All stations had a depth range of $4480-4649 \mathrm{~m}$ and nodule presence/absence was considered to be the main factor determining most of the differences between the three sampling stations. 
113

\subsection{Sampling strategy and sample processing}

\subsection{1}

Abiotic variables

The environmental differences between the three stations were estimated from a total of eleven MUC (sediment biogeochemistry: four at a Nodfree station, four at the nodule-rich station Nodrich_B and three at Nodrich_A; supplementary table ST1). Upon recovery, the cores (PVC cores of $10 \mathrm{~cm}$ diameter) removed from the MUC were transferred to a cold lab container set at a temperature of $+4^{\circ} \mathrm{C}$. Before processing, the cores were examined for the presence of nodules. The sediment was sliced per $1 \mathrm{~cm}$ layer till a depth of $10 \mathrm{~cm}$ and storage was specific for the type of analysis: pigments (Chlorophyll-a and Phaeopigments) at $-80^{\circ} \mathrm{C}$; total organic carbon (TOC), total nitrogen (TN) and grain size at $-20^{\circ} \mathrm{C}$. Each sediment slice for the analyses of grain size, TOC and TN was dried at $60^{\circ} \mathrm{C}$ overnight in the laboratory in Ghent, Belgium. After drying, $1 \mathrm{~g}$ of sediment was analysed with a Malvern Mastersizer Hydro $2000 \mathrm{G}$ for granulometry. The granulometric parameters used within this study are median grain size (Median_gs), sorting coefficient (Grain_SC), sand (grain size $>63 \mu \mathrm{m})$, silt $(4 \mu \mathrm{m}<$ grain size $<63 \mu \mathrm{m})$, and clay (grain size $<4 \mu \mathrm{m}$ ) content (\%) as well as porosity (\% vol.). The sorting of the sediment as a measure of the spread of the various grain size classes, was quantified by the sediment sorting coefficient (Grain_SC), calculated following Giere (2009) as:

$S C=\frac{\varphi 2 \mathrm{~s}-\varphi 7 \mathrm{~s}}{2}$

With $\phi 2 s$ and $\phi 7 s$ being the logarithm (base 2) of the first and third quartile of the sediment grain size frequency distribution. The higher the value of Grain_SC, the less well sorted the sediment is and the more it is represented by one grain size class. Porosity $(\phi)$ was estimated assuming a dry sediment density of $2.55 \mathrm{~g} \mathrm{~cm}^{-3}$ and making use of the formula:

$$
\varphi=\frac{\frac{\text { weight of water }}{\text { density of water }}}{\frac{\text { weight of dry sediment }+ \text { weight of water }}{\text { density of water }}}
$$


Total organic carbon (TOC) and total nitrogen (TN) were measured on samples of $200 \mathrm{mg}$ using a Flash

2000 NC Sediment Analyser of Interscience (Thermo scientific). These samples were acidified with 1\%

$\mathrm{HCl}$ to remove inorganic carbon prior to analysis. The (molar) sediment total organic carbon to total nitrogen ratio (TOC/TN) was computed as:

$$
\frac{T O C}{T N}=\frac{\frac{T O C}{12}}{\frac{T N}{14}}
$$

141 Pigment analysis was carried out for each $1 \mathrm{~cm}$ layer on the $0-5 \mathrm{~cm}$ layer profile by means of High Per-

142 formance Liquid Chromatography (Agilent 1200 Infinity II, Agilent Technologies, Diegem, Belgium). Chlo-

143 rophyll-a and its breakdown product phaeophytin-a were measured and their sum as chloroplastic pig-

144 ments equivalent (CPE) calculated. Nodule coverage was calculated on eleven box-corers deployments 145 that were retrieved for the macrofauna sampling (see next section for more details). The nodule abundance and coverage was calculated by GSR staff with two methods: i) from each individual box-corer each nodule was weighed and the sum of the weights was divided by the box-corer surface $\left(0.25 \mathrm{~m}^{2}\right)$; ii) for AUV imagery the surface was estimated as the percentage of the total box-corer surface occupied by the nodules based on photographs taken after the overlying water was siphoned out of the newly retrieved box-corer on deck (see next section on macrofauna assemblage sample processing for more 151 details).

153 For the sampling of the macrobenthic fauna, a point-sampler stainless steel box-corer (BC, 0.5 length $\mathrm{x}$ $1540.5 \mathrm{~m}$ width, $0.6 \mathrm{~cm}$ height) was used. Four box-corer deployments were successfully conducted at Nod155 free and Nodrich_B, whereas only three box-corer deployments were successful at Nodrich_A. For each 156 box-corer deployment a MUC sample was taken at the same location (supplementary table ST1), allow157 ing for inference on the possible relationships between the community composition and the local envi158 ronmental variables. Upon retrieval, the sediment-overlying water was removed from the box-corer and 159 filtered upon a $300 \mu \mathrm{m}$ sieve to retain all possible macrofauna organisms present in the overlying water. 160 Once the water and surficial nodules were removed, the sediment within the box-corer was sliced in 0-3 $\mathrm{cm}, 3-5$ and $5-10 \mathrm{~cm}$ layers by means of a ruler and spatulas. The sediment collected by slicing, was 
transported submerged in cold filtered sea water into a climate room set at $+4^{\circ} \mathrm{C}$ to be live sieved (300 $\mu \mathrm{m})$. The sieved macrofauna was collected and fixed in prechilled non-denatured $96 \% \mathrm{EtOH}\left(-20^{\circ} \mathrm{C}\right)$ for further identification (to the lowest taxonomic level possible), which was done in the laboratory back in Belgium. Identification was carried out on ice and in pre-filtered seawater (on board) or Milli-Q water (later in the laboratory) to avoid DNA degradation for further DNA barcoding (results not discussed here). Identification to species level was done only for the most abundant taxa: Isopoda, Polychaeta, Tanaidacea. When the identification of intact specimens to species/family level was not possible with absolute certainty, the most closely resembling species/family was chosen and a "cf." annotation was mentioned next to the species name. The identification of intact specimens was done by expert taxonomists (co-authors of this paper, see Contribution section) using identification keys and original taxonomic descriptions. Total counts per box-corer were extrapolated to densities (number of individuals per square meter, ind. $\mathrm{m}^{-2}$ ) to allow comparison with other studies. The higher-taxon processing included the counting of macrofauna-size meiofaunal taxa (total counts are reported in the supplementary Table ST2) but it was decided not to include these data in the analyses for comparability with other studies.

One of the interests of this paper was to identify possible differences in environmental variables, community composition and higher/lower-taxon diversity between nodule-rich and nodule-free stations. Since the replication of a nodule-free station was not possible (only one nodule-free station was sampled) during the GSRNOD17 cruise, the analysis of the collected data was carried out considering all the stations separately (factor "Station" $=3$ levels: Nodfree, Nodrich_A, Nodrich_B). All statistical analyses results are reported in Table $1 \mathrm{a}$ and $\mathrm{b}$ (main test) and in supplementary material Table ST3 $\mathrm{a}$ and $\mathrm{b}$ (pair-wise comparisons). All analyses were performed in R with the use of the RStudio interface (version 1.2.1335, R Core Team, 2020). Both the univariate (e.g. nodule abundance, individual sediment characteristics/individual pigment concentrations, total density, main taxa relative abundance, and diversity indices) and the multivariate (e.g. all environmental variables excl. nodule abundance / highertaxon abundances) datasets were tested for differences by means of a One-way (only factor : Station) or Two-way (with as factors: Station, Layer and their interaction) Permutational Multivariate Analysis of 
Variance (Permanova). The analysis were computed based on a Euclidean distance dissimilarity matrix for all the univariate datasets (raw data) and the environmental variable multivariate dataset (normalised raw data), whereas a Bray-Curtis similarity matrix was calculated for the higher-taxon multivariate dataset on square-root transformed density data (ind. m-2). Where a significant effect was found, PermDisp analysis was done to confirm homogeneity of dispersions between groups and interpret the Permanova results. If significance was confirmed, a pair-wise test was carried out to identify the stations that differed from one another. The analyses were executed making use of the following R packages: "vegan" (for the Permanova analysis, version 2.5.5, Oksanen et al., 2019), "RVAideMemoire" (for MANOVA pair-wise testing, version 0.9-73, Hervé, 2020), "stats" (for the post hoc t-test, version 3.6.1, R Core Team, 2020), "ecodist" (for dissimilarity based functions, version 2.0.1, Goslee and Urban, 2020), "fossil" (for Chao1 asymptotic diversity estimator, version 0.3 .7 , Vavrek, 2020) and "iNext" (Interpolation and Extrapolation of Species Diversity, version 2.0.19, Hsieh and Chao, 2019). To visualise the number of unique and shared species and families per taxon as a set of intersections between the three stations, we used the upset() function in the "UpSetR" package (version 1.4.0, Gehlenborg, 2019). In the iNext package, the Authors make use of Hill numbers for abundance data to estimate the asymptotic diversity. In our study we used for this estimation $q=0$ (for more details see ; Hsieh et al., 2016) which equals to the simple species (taxon) richness, which counts species regardless of their relative abundance (Chao et al., 2014).

\subsubsection{Abiotic variables analysis}

A multivariate two-way permanova was carried out on the $0-5 \mathrm{~cm}$ and $5-10 \mathrm{~cm}$ profiles for all variables (excl. nodule abundance), with pigments being absent for the deeper 5-10 cm layer. The univariate statistical analyses pertaining to the pigments were carried out separately from the other environmental variables since the data was analysed across a higher resolution sediment profiling and reported as such to avoid loss of information during analysis. Differences in individual pigment concentrations (Chl-a, Phaeopigments, CPE) between stations were analysed across five surface sediment layers $(0-1,1-2,2-3$, $3-4,4-5 \mathrm{~cm}$ ) whereas the other environmental variables (granulometry, TOC, TN) were analysed for the two bulk depth profiles $0-5$ and 5-10 cm. To visualise the sediment environmental data a Principal Coordinate Analysis (PCA) was built on a Euclidean distance-base dissimilarity matrix of the complete dataset 
216 (including the pigments - as bulk $0-5 \mathrm{~cm}$ - but excl. nodule abundance) normalised data (Figure 2) and 217 group confidence interval (0.95) ellipses were constructed. Average values (with standard deviation) of 218 the investigated parameters are reported in Table 2. For completeness, we provide two PCA plots for the $219 \quad 0-5$ and $5-10 \mathrm{~cm}$ depth profile for the sole sediment abiotic variables (without the pigments and nodule 220 abundance) in the supplementary material Figure SF1 and SF2.

221 To have a proxy for surface water productivity we extracted VGPM (Vertically Generalized Production Model) based on MODIS satellite data for January 2015 - June 2017 (1080 x 2160 files $)$ and estimated net primary productivity (NPP, Figure 3; Behrenfeld and Falkowski, 1997). In order to account for timelagged responses in faunal and abiotic characteristics (Miljutin et al., 2015), we set the start of the estimation period to nine months prior to the GSRNOD15A sampling campaign. Monthly-averaged NPP values were downloaded as HDF files (http://www.science.oregonstate.edu/ocean.productivity/index.php), converted to geotiff (using SeaDAS) and finally perfected in QGIS v2.18 when a convex hull was drawn around the positions of all biological deployments and the Zonal statistics tool was used to compute monthly averaged NPP.

\subsubsection{Macrofauna higher-taxon analysis}

231 Because of the low densities, the macrofauna higher-taxon assemblage was analysed in bulk merging the $0-3,3-5 \mathrm{~cm}$ and $5-10 \mathrm{~cm}$ layer (hence as bulk $0-10 \mathrm{~cm}$ ). All results of univariate and multivariate analyses are reported in Table $1 \mathrm{~b}$ and ST3 $\mathrm{b}$.

\subsubsection{Diversity analysis}

To compare species/family diversity for each of the three dominant taxa and higher phylum/order level for the macrofauna higher-taxon dataset, we carried out multiple One-way Permanova on the estimated diversity indices for each taxon separately (Table 1 b). For this study we selected i) the species/taxon richness number (S or T), ii) the Shannon - Wiener index $\left(\mathrm{H}^{\prime}\right)$ iii) The Pielou's evenness index and iv) the rarefaction method of Sanders (1968), perfectioned by Hurlbert (1971), of expected species (ES(n)) for a specific sample size (smaller or equal to the effective $n=$ minimum taxon number; for average values see Table 3). 
To visually portray the distribution of species and families between stations (shared versus unique species/families) we produced three plots (one per taxon, Figure 4 a-c) each displaying both the species and the family shared/unique counts across the three sites. A list of unique (found only at one specific station across all samples) and singleton (encountered only once across all samples) species is given in the supplementary material Table ST4. Finally, a plot with the average relative abundance of the families per taxon per station and for the whole B4S03 site is presented in Figure 5.

\subsubsection{Asymptotic diversity analysis (low taxonomic level)}

To understand the efficiency of our sampling effort in capturing the local diversity (B4S03 site) for the three most dominant taxa, we used the R package "fossil" to compute for both species and family level the non-parametric asymptotic richness estimator Chao1 (see Table 4). In this study we focused our analysis on the Chao1 estimator which is a widely used non-parametric estimator of species richness for abundance data which takes into consideration the number of singletons (number of species represented by one singular individual across samples) and doubletons (species represented by two individuals across samples) in the data matrix (Chao et al., 2009). To estimate the minimum number of additional individuals/samples or sampling area necessary to detect different proportions (with $\mathrm{g}=1$ representing $100 \%$ of the estimated diversity) of the estimated $\mathrm{S}_{\text {Chao1 }}$ asymptotic richness for the whole B4S03 site we made use of the Excel Calculator for abundance data (using total counts) as provided in the Appendix by Chao et al. (2009). To visually display the standardised species richness estimation and the sample coverage based on the Hill's numbers (in our case we used $q=0$ which gives the familiar species accumulation curve based on individuals) we made use of the "Sample Size-Based Rarefaction/Extrapolation" curves (with confidence intervals, Hsieh and Chao, 2019) calculated by means of the iNext() function from the "iNext" R package (Hsieh and Chao, 2019) and based on individuals numbers (in light of the small sample size of this survey, $n=10$ ). We produced two sets of graphs: i) Figure 6 a-d presents the and family) across the whole site B4S03. 


\section{Results}

Average values are reported with their standard deviation. All results, including statistics, are reported in Table $1 \mathrm{a}$ and $\mathrm{b}$ (main test and permdisp results) and in supplementary table ST3 $\mathrm{a}$ and $\mathrm{b}$ (permdisp and pair-wise tests).

\subsection{Abiotic variables}

The multivariate PERMANOVA based on the environmental variables (excl. pigments) did not find significant differences between stations but detected significant differences between layers $(0-5 \mathrm{~cm}$ versus 5 $10 \mathrm{~cm}$ layer), although the significant Permdisp test suggests caution in the interpretation of the significance of the main test (Table $1 \mathrm{a}$ and ST3 a). When looking at single variables, the nodule coverage was significantly higher at the two nodule-rich stations compared to Nodfree. Nodule abundance $\left(\mathrm{kg} \mathrm{m}^{-2}\right)$ statistical analysis showed a significant difference between the two nodule-rich and the nodule-free stations. The sediments of B4S03 site were dominated by silt (>70\%) followed by clay $(>15 \%)$ and sand $(>6 \%)$ in all the investigated stations (Table 2). On the one hand, the percentage of sand and silt did not differ between stations and/or between layers. Clay\%, on the other hand, displayed significant differences between Nodfree and Nodrich_A (higher clay content in Nodrich_A) and non-significant pair-wise t-test for Nodfree-Nodrich_B pair. Clay content showed the largest variance at Nodrich_B, which showed the highest clay content of the 0-5 cm layer, whereas Nodrich_A had higher clay content in the deeper layer. The median gran size (Median_GS) showed the largest variance at Nodrich_B with no significant differences between stations and/or layers. Porosity was higher in the upper 0-5 cm layer in all three stations. Total organic carbon (TOC\%) ranged from a maximum of $0.62 \pm 0.03 \%$ in Nodrich_A $0-5 \mathrm{~cm}$ layer to a minimum of $0.52 \pm 0.03 \%$ in Nodfree $5-10 \mathrm{~cm}$ layer, displaying the largest variance in Nodrich_B, and showed a significant decrease with increasing sediment depth across all stations (Table 2). Total nitrogen (TN) and TOC/TN showed no significant differences between stations and/or the layer depth (Table 2).

The pigment concentrations in the sediment layers were all near detection level, with the highest values recorded at Nodfree for Chl-a and CPE and at Nodrich_B for phaeopigments. The univariate Chlorophyll- 
a analysis tested significant for the interaction factor, but when the pair-wise t-test was performed no significantly different pairs were detected. This may be explained by the significant PermDisp and /or by the low number of replicates (Table 1 a and ST3 a). The phaeopigments analysis also showed a significant interaction factor with the $0-1 \mathrm{~cm}$ layer differing significantly from all other layers only within station Nodfree. Again, the significant PermDisp test result urges caution in the interpretation of the significant main test results. Likewise, the CPE analysis showed the same pattern with a significant interaction factor and significant differences of the $0-1 \mathrm{~cm}$ layer from the deeper layers at the nodule-free station. Again, differences in the dispersion of the group variances may be the cause for these significant differences.

Overall, when looking at the Principal Component Analysis for the surface layer $(0-5 \mathrm{~cm})$ in Figure 2, we can observe how the two nodule-rich sites displayed a relatively larger within-station variability, with Nodrich_B showing the largest confidence interval (c.i.) ellipse. Moreover, the two nodule-rich stations's ellipses considerably overlapped and their centroids were also very close to each other. Nodfree's centroid separated from the two nodule-rich stations's centroid along PC2 axis (explaining 26.5\%) but the ellipse also overlapped with Nodrich_B. The PCA therefore points to non-significant differences between the stations based on the multivariate sediment characteristics of the surface layer front.

The Net Primary Production (NPP, Figure 3) was estimated from monthly-averaged surface for B4S03 site from the period January 2015 - June 2017 and it shows a maximum NPP peak in May 2016 (about 360 $\mathrm{mg} \mathrm{C} \mathrm{m} \mathrm{m}^{-2} \mathrm{~d}^{-1}$ ) and the lowest in September of the same year.

\subsection{Macrofauna analysis}

The macrofauna assemblages from B4S03 showed total macrofaunal densities (excl. meiofauna) of $176 \pm$ 36 individuals $\mathrm{m}^{-2}$ at the nodule-free station, $178 \pm 30$ individuals $\mathrm{m}^{-2}$ at Nodrich_A and $147 \pm 57$ individuals $\mathrm{m}^{-2}$ Nodrich_B (see supplementary material Table ST2). The univariate Permanova showed no significant differences between stations (Table $1 \mathrm{~b}$ and ST3 b). Both the maximum total density of 212 individuals $\mathrm{m}^{-2}$ and the minimum of 64 individuals $\mathrm{m}^{-2}$ were estimated from box-cores collected at the southern nodule - rich station Nodrich_B. A total of 10 identified higher taxa were found across all samples (Table ST1). The dominant taxa were Polychaeta (average relative abundance: $52 \pm 9.8 \%$ Nodfree; 
$48 \pm 15.6 \%$ Nodrich_B; $65 \pm 17.3 \%$ Nodrich_A), Tanaidacea (average relative abundance: $19 \pm 5.3 \%$ Nodfree; $16 \pm 6.4 \%$ Nodrich_B; $13 \pm 13.6 \%$ Nodrich_A) and Isopoda (average relative abundance: $21 \pm 12 \%$ Nodfree; $11 \pm 6.7 \%$ Nodrich_B; $7 \pm 2.8 \%$ Nodrich_A), which together on average comprised the $91 \%$, $75 \%$ and $85 \%$ of the total fauna at Nodfree, Nodrich_B and Nodrich_A respectively. Finally, the multivariate analysis at the higher-taxon level of the macrofauna densities showed no statistically significant differences in assemblage composition between the three stations (Table $1 \mathrm{~b}$ ).

\subsection{1}

\section{Dominant taxa diversity and distribution}

Combining all samples, at $\mathrm{B} 4 \mathrm{SO} 03$ site, a total of 89 species belonging to 35 families were identified across all three taxa (see Figure 4). Of these species, 49 were represented in the samples as singletons (> 50\%), 20 doubletons and another 21 were encountered more than twice (Table 5, also see supplementary material ST4 for list of species). In general, for each of the identified taxa, the diversity indices (taxon richness (T or S), Shannon-Wiener H', Pileou's evenness J', the expected taxon number ET(n)) were estimated for species and family taxonomical level (see Table 3). No statistically significant differences were found between stations for any of the estimated diversity indices in any of the analyses for any of the taxa (Table $1 \mathrm{~b})$.

Looking at species and family distribution across all stations combining the three taxa (Figure $4 \mathrm{~d}$ ), we observed that the total number of species identified at the three stations was very similar (Nodfree $=42$ species; Nodrich_B $=43$ species; Nodrich_A $=42$ species) whereas Nodrich_B showed the highest number of families (29) followed by Nodrich_A with 27 families and Nodfree with 23 families. In total 11 species were shared among the three stations, 23 species were unique to Nodrich_A, 21 to Nodrich_B and 18 to Nodfree. When looking at family level, 16 families out of 37 were shared among the three stations when the combined diversity was considered. Nodfree and Nodrich_B stations (the southernmost sampling locations) both showed 5 unique families (all of them singletons) and Nodrich_A displayed 3 unique families.

\subsubsection{Isopoda}

Of the 31 isopod individuals identified to species level, a total of 17 morphospecies belonging to five families was observed (Figure 5). Of these, only two were shared among the three stations (see Figure 
4a), and 14 were unique across the stations (see Table ST4): 6 species (belonging to 4 families; 4 were singletons) were found only at the nodule-free station, another 6 (belonging to 2 families; 3 were singletons) at the Nodrich_A and only 2 species (belonging to 2 families; both were singletons) at Nodrich_B. The asymptotic diversity estimation based on the Chao1 estimator computed a total of 25 species to be recorded in the $\mathrm{B} 4 \mathrm{SO} 3$ site across an estimated total of 7 families (Table 4). Based on this number we can state to have collected $68 \%$ of the total expected isopod diversity based on the numbers of samples and individuals identified. If we were to estimate the total species diversity as computed by the non-parametric asymptotic estimator Chao1 $(\mathrm{g}=1$ as calculated with the Chao1 excel calculator (Chao et al., 2009), see Table 4), we would have to collect an additional 41 samples for a total of 126 individuals, or sample a total surface area of $13 \mathrm{~m}^{2}$. If, as suggested by Chao et al. (2009) we were to select a fraction of the total estimated diversity to encompass most taxa with more realistic sampling objectives, we would need to sample $95 \%$ of the total estimated diversity ( $g=0.95$, Table 4 ), and, in our case study, for Isopoda we would need an additional 33 individuals or a total of 21 samples $\left(5 \mathrm{~m}^{2}\right)$ from the site. The relative abundances of the six Isopoda families (Figure 5, Supplementary Table ST5) for the B4S03 site were Desmosomatidae (37\%) followed by Nannoniscidae (25\%), Dendrotionidae (22\%), Thambematidae (9\%), Haploniscidae (3\%) and Macrostylidae (3\%) The most dominant species were Dendrotion species A (belonging to the family Dendrotionidae, rel. abundance 21\%), Eugerdella species A (belonging to the family Desmosomatidae, rel. abundance 9\%) and Thambema species A (belonging to the family Thambematidae, rel. abundance 9\%).

\subsubsection{Polychaeta}

A total of 46 species belonging to 20 families have been delimited amongst the 104 polychaete individuals found in our samples. Of these, only 7 species were shared between all stations (Figure $4 \mathrm{~b}$ ). Nodrich_A presented the highest number of unique species (15, of which 13 were singletons), followed by Nodrich_B (9, all singletons) and Nodfree (6, of which two were singletons). The Chao1 asymptotic species diversity $\left(\mathrm{S}_{\mathrm{Cha01}}\right)$ estimator computed a total expected species richness of 74.8 species to be recorded across a total of 26 families (Table 4). We therefore collected $61 \%$ of the expected species diversity and $76 \%$ of the expected family diversity during our current sampling effort. In order to collect the total 
expected species richness ( $g=1$, Table 4) we would need an additional 745 individuals from 72 samples

comprising a sampled area of $20 \mathrm{~m}^{2}$ in total. In order to reach $95 \%$ of the Chao1-expected total species diversity we would need to collect 336 individuals or 42 samples covering $11 \mathrm{~m}^{2}$ in total. Species were evenly represented across the whole site, with most species representing less than $2 \%$ of the total iden-

tified individuals. The most dominant species for the B4S03 site were Aurospio dibranchiata ID \#1457

(Spionidae, rel. abundance 9\%), Bathyglicinde cf. B. profunda (Goniadidae, rel. abundance 7\%), Aurospio

dibranchiate ID \#249 (Spionidae, rel.abundance 6\%), Prionospio sp. (ID \#268, family Spionidae, rel. abun-

dance 6\%), Paraonides sp. ID \#397 (family Spionidae, rel. abundance 6\%) and Paralacydonia paradoxa

(only species of the family Paralacydoniidae, rel. abundance 4\%). The most dominant families (Figure 5 ,

Supplementary Table ST5) for the B4S03 site were Spionidae (30\%), Cirratulidae (15\%) and Goniadidae

(10\%) with the rest of the families representing each $\leq 5 \%$ of the total identified organisms.

\subsubsection{Tanaidacea}

The Tanaidacea comprised 28 morphospecies belonging to 9 families across 62 identified individuals, of

which only 2 species were shared among all the stations, and 21 species were unique: 6 (3 singletons) only occurring at Nodfree station, 2 (both singletons) at Nodrich_A and 13 (11 singletons, and possibly 4 new genera) only occurring at Nodrich_B (Figure 4c, Tables 4, ST4). The Chao1 asymptotic diversity estimation for the B4S03 site resulted in 53.6 species which means that our current sampling effort accounted for $52 \%$ of the expected Tanaidacea diversity $S_{\text {Chao1. }}$. The Chao1 estimator computed a total of 10.5 estimated families for the site, indicating the $80-90 \%$ of diversity expected was recorded with our sampling effort. If we were to sample the entire estimated species diversity $S_{\text {Chao1 }}(g=1$, Table 4$)$ additional 575 individuals from 93 box-cores and a total area of $26 \mathrm{~m}^{2}$ would need to be sampled. When we would plan to sample $95 \%$ of $\mathrm{S}_{\text {Chao1 }}(\mathrm{g}=0.95$, Table 4), we would need to collect an additional 155 individuals, or a total of 35 samples and $9 \mathrm{~m}^{2}$ of area. When considering the whole B4S03 site, the majority of Tanaidacea species represented less than $4 \%$ of the total identified individuals. The most dominant species were Forcipatia sp. ID \#6 (belonging to the family Leptognathiidae, rel. abundance 14\%), Thumidochelia sp. ID \#157 (from the family Akanthophoreidae, rel. abundance 8\%), Stenotanais sp. (ID \#59, from the family 400 Akanthophoreidae, relative abundance 6\%) and Caudalonga sp. ID \#74 (from the family Colletteidae, rel. 401 abundance 6\%). The most dominant families were Akantophoreidae (32\%), Leptognathiidae (19\%), and Colletteidae (10\%); as many as $18 \%$ of all tanaidaceans (represented by Insociabilitanais sp. ID \#160 and 
404

405

406

407

408

409

410

systematic are grouped as Paratanoidea family incertae sedis (see http://www.marinespecies.org/aphia.php?p=taxdetails\&id=246697). In order not to lose information, we included this superfamily as family in the analysis.

\section{Discussion}

\subsection{Abiotic variables}

\subsection{1}

Sediment characteristics

In general, the B4S03 site sediments seemed to be relatively similar between the three stations. Likewise to other deep-sea abyssal plains and other areas within the CCFZ (Khripounoff et al., 2006; Smith et al., 2008a; De Smet et al., 2017), the stations' sea bottoms were formed by about $90 \%$ of very fine particles (below $63 \mu \mathrm{m}$ ), of which the largest fraction was silt $(4-63 \mu \mathrm{m}$, on average $72 \%)$. The concentrations of total organic carbon found within this study were comparable to those of another GSR contract site (B4N01 more to the west, TOC\% $=0.54 \pm 0.02$, de Smet et al., 2017), but higher than those recorded during the previous expedition GSRNOD15A by De Smet et al. (2017) in the same site (B4S03, TOC\% = $0.41 \pm 0.01$ ) and in another GSR contract site (B6S02 more to the east, TOC\% $=0.49 \pm 0.02$ ). Similarly, the values found within this study were larger than those recorded by Khripounoff et al. (2006, TOC\% = 0.48) for the NIXO zone (Ifremer; $14^{\circ} 02^{\prime} \mathrm{N}, 130^{\circ} 07^{\prime} \mathrm{W}$ ) within the CCFZ nodule fields. Across all analyses (multivariate and univariate) no consistent and/or significant differences between the two nodulerich and the nodule-free sites were found, hence confirming our initial expectation. Nevertheless, from the PCA computed on the surface layer $(0-5 \mathrm{~cm}$, Figure 2) making use of all abiotic variables, we can observe how the nodule-rich stations' ellipses overlap significantly and their centroids segregate from that of the nodule-rich station ellipse. The ellipses incomplete segregation between the nodule-rich and nodule-free stations may be due to Nodrich_B large within-group variance and the overall low number of replication in a highly patchy environment (e.g. the sedimentary matrix) which in turn might hinder the detection of potentially meaningful differences in surface sedimentary features at the three sites. 
432

433

434

435

436

437

438

439

440

441

442

443

444

445

446

447

448

449

450

451

452

453

454

455

456

457

458

459

460

461

462

463

464

Sediment TOC in deep-sea sediments depends on the particulate organic carbon (POC) flux from the euphotic zone and the depth (Lutz et al., 2007), with only part of the produced organic matter sinking on the seafloor (Smith et al., 2018) and being mostly refractory in nature when reaching abyssal depths (Smith et al., 2008b; Arndt et al., 2013). The CCFZ is characterised by very low surface productivity which follows a gradient from higher to lower POC fluxes from east to west (Smith and Demopoulos, 2003). These POC fluxes are mirrored in the benthic abundances, which have also been reported to follow such westward decline along the CCFZ (Paul and Hecker, 1979; Smith et al., 2008a; De Smet et al., 2017; Wilson, 2017). Regional interannual and seasonal variability in surface primary production can be a possible explanation for the higher TOC values recorded at B4S03 during GSRNOD17 compared to GSRNOD15A (De Smet et al., 2017). From the NPP satellite-derived primary productivity estimations (Figure 3 ) we can notice how the GSRNOD15A cruise (October 2015) took place about 20 weeks after a NPP peak of about $280 \mathrm{mg} \mathrm{C} \mathrm{m}^{-2} \mathrm{~d}^{-1}$ in the area, whereas GSRNOD17 was conducted only eight weeks after a NPP peak of about $270 \mathrm{mg} \mathrm{C} \mathrm{m}^{-2}$ $\mathrm{d}^{-1}$. Smith et al. (2018) estimated that a time of 0-70 days is needed for surface primary production to be exported as POC to abyssal depths. Therefore, the residence time of the portion of NPP that would have reached our sediments in 2017 would have been shorter compared to the GSRNOD15A conditions. In the abyss of oligotrophic oceanic areas, the initial consumption of the organic matter fraction depositing on the surface sediment layer is expected to be done by bacteria, followed by surface protozoans (e.g., Gooday and Rathburn, 1999; Gooday, 2002; Sweetman et al., 2019). In our study TOC decreased slightly yet significantly with increasing sediment depth across all three stations, pointing at both potential initial remineralisation and also to rather efficient vertical organic matter mixing, likely via bioturbation. Nevertheless, additional sampling is necessary to properly quantify the effective NPP that reaches the CCFZ nodule fields sediments (by using e.g. sediment traps) and their inhabiting biota since it represents valuable information for the understanding of the role that these ecosystems play in the global carbon flux and carbon sequestration in light also of the future of deep-sea mining in these areas (Straatmann et al. 2019).

\subsection{Macrofauna assemblage structure and diversity}

The soft sediment macrofauna investigated in this study showed no clear pattern in relation to the presence/absence of nodules. This contrasts with what Vanreusel et al. (2016) observed for epifaunal organisms in the CCFZ, where entire functional groups (mainly antipatharian corals and alcyonarians) were absent in nodule-free transects sampled by video surveys. In comparison with studies that used the same sampling gear (box-corer of $0.25 \mathrm{~m}^{2}$ surface area) and investigated the same benthic component (soft sediment benthos), we can state that the average densities recorded for B4S03 macrofauna assem- 
blage described here were relatively low compared to the abundances reported by Wilson et al. (2017) for the western sites PRA (NOAA designated "Provisional Interim Protected Reserve Area", $774 \pm 254$ SD ind. $\left.\mathrm{m}^{-2}\right)$ and Domes $C\left(370 \pm 123\right.$ SD ind. $\left.\mathrm{m}^{-2}\right)$ in the CCFZ, but in the same range of those reported in the first baseline assessment for Dome C (152.44 \pm 2.8 SE) by Hecker and Paul (1979). The sampling effort was always much larger in these studies (Wilson et al., 2017: 71 box-corers at DOME C across three sampling events; 16 box-corers at PRA; Hecker and Paul, 1979: 38 box-corers at DOME C) compared to the present study. The observed relative abundances of the three dominant taxa are comparable to those recorded elsewhere in the CCFZ, where Polychaeta were always the dominant group, followed by either isopods or tanaids (Hessler and Jumars, 1974; Paul and Hecker, 1979; De Smet et al., 2017; Wilson, 2017; Bonifácio et al., 2020).

4.2.1

Isopoda

The same dominant families found in this study were highly representative for the GSR contract area's B4S03, B4N01 and B6S02 sites investigated during a previous sampling cruise GSRNOD15A by De Smet et al., (2017). During that study, the authors identified some families of isopods not encountered (Ischnomesidae) or encountered in significantly lower overall relative abundances (Macrostylidae) in the present study. During GSRNOD15A, the Macrostylidae, represented mostly by Macrostylis metallicola (Riehl and De Smet 2020), were found to be relatively abundant across the three sites of the GSR contract area. In the present sampling the entire family was found to show much lower relative abundance when considering B4S03 as a whole, and the most representative species was confirmed to be Macrostylis metallicola by $16 \mathrm{~S}$ rRNA barcoding analysis (Riehl and De Smet 2020). The low relative presence of Macrostylidae is surprising considering that in other CCFZ areas (Janssen et al., 2015, 2019; De Smet et al., 2017) and in abyssal sediments in general (e.g., Wilson, 2008; Elsner et al., 2015) this family is often one of the most abundant isopod groups. Considering their occurrence in virtually all open-ocean abyssal sediments studied with appropriate gear (e.g., box-corer or epibenthic sledge;) as well as patchy distributions of abyssal macrofauna (Kaiser et al., 2007; Jóźwiak et al., 2020) the absence of Macrostylidae from our samples (specifically from the nodule-rich stations) is probably due to under-sampling. 
491 The family Ischnomesidae was absent during our sampling effort across all stations. De Smet et al., 492 (2017) observed Ischnomesidae in B6S02; however, it was absent in GSR sites B4S03 and B4N01 during 493 the GSRNOD15A cruise sampling. Ischnomesidae species distribution and population structure has been 494 investigated in the North West Pacific where an abyssal trench (with hadal depths of maximum 9604 m) 495 is known to constitute a dispersal barrier for many of the isopod species found in the area (Bober et al., 496 2019). The authors found that hadal species of Ischnomesidae had a poor dispersal ability at distances 497 larger than about $300 \mathrm{~km}$ (Bober et al., 2019) and that no lineages were found to cross the trench. The 498 distance between $\mathrm{B} 4 \mathrm{SO} 3$ and $\mathrm{B} 6 \mathrm{SO} 02$ is about $300 \mathrm{~km}$, potentially indicating that if species belonging to 499 this family have very little dispersal potential, their distribution may be limited to specific parts of the 500 GSR contract area. Nevertheless, more information on POC fluxes and bottom currents' strength and 501 direction are needed to understand species distribution. Further, like in Macrostylidae, expansion of 502 ischnomesid populations into our study area could have easily occurred over long time spans outweigh503 ing the low-dispersal argument, and the lack of large deep-sea mountain chains between the two GSR contract sites (B6S02 and B4S03) would support this opposition. Other isopod families that could have been expected in the samples but was represented neither in our nor in De Smet et al.'s (2017) samples are the Munnopsidae and Haploniscidae. Munnopsidae was, however, found in the CCFZ by Janssen et al. (2015) in a study based on epibenthic sled samples. Most munnopsids are highly motile and have a rather epibenthic or hyperbenthic lifestyle and Haploniscidae have an epibenthic lifestyle as well. In abyssal epibenthic sledge samples these groups are often dominating the isopod fraction of the macrofauna (Meyer-Löbbecke et al., 2014; Golovan et al., 2019) but not so in box-corer samples (Wilson, 2008) indicating a gear-dependent bias. Previous studies showed that epibenthic isopods are more affected by turbulence than inbenthic groups (Thistle and Wilson, 1987, 1996). The box-corer creates a bow-wave effect before touch down which may affect the epibenthic groups thus reducing their representation while the epibenthic sledge may underrepresent inbenthic groups sliding on the sediment surface (Jóźwiak et al., 2020). We hence consider sampling bias to be the most likely explanation for Ischnomesidae to be absent from our samples. A lack of representation of two isopod families is supported by our estimation of isopod diversity in the area. 
518 De Smet et al. (2017) collected 12 box-corer samples during GSRNOD15A in two GSR contract sub-areas

519 (B4 and B6) at three stations within the sites B4S03, B4N01, B6S02. The authors recorded 18 isopod spe-

520 cies with only $11 \%$ of the taxa being shared across the three sites, and computed a $\mathrm{S}_{\text {Chao1 }}$ of 26 species.

521 Considering the high patchiness of abyssal Asellota (Kaiser et al., 2007; Wilson, 2008) and the large dis-

522 tance $(250-300 \mathrm{~km})$ between the three sites, we can presume that the Chao1 diversity estimator under-

523 estimated the species diversity during the study of De Smet et al. (2017), because during the current

524 study which is based on 10 box-corer samples, we recorded in B4S03 a total of seventeen species and

525 estimated a species richness of 25 species. However, as discussed above, number of box-corers used during our investigation are yet to be considered limited in light of the low abundances and distribution of deep-sea isopods. This renders our results prone to sampling bias and may still limit our capacity to accurately estimate isopod diversity and distributional patterns, with an overall overestimation of endemism and an underestimation of the total local and regional diversity.

532 The dominance of spionids among other Polychaeta families had been already observed by (Bonifácio et 533 al., 2020) during a much more intensive (30 box-corer samples) and extensive sampling (five areas over $5341440 \mathrm{~km}$ along the eastern side of the CCFZ). In particular, during their study, spionids were dominant 535 across the eastern Ifremer (34\%), GSR (B6S02 site, 27\%) and IOM (19\%) contract areas, whereas the protected area APEI\#3 (Area of Particular Ecological Interest) and the contract area BGR were dominated by the cirratulids, the second most dominant group in our investigation. Interestingly, these authors observed a turnover in the species composition between the eastern sites (BGR, IOM and GSR), characterized by a lumbrinerid species, and the western locations (eastern Ifremer and APEI\#3), characterised by spionids, cirratulid, paraonid, maldanid and opheliid. Also Smith et al. (2008) described the biodiversity and species range of polychaetes in the CCFZ comparing an eastern (E site, centered at $\sim 15^{\circ} \mathrm{N}, 119^{\circ} \mathrm{W}$, in specific the IOM contract area), a central ( $C$ site, centred at $\sim 14^{\circ} 5^{\prime} \mathrm{N}, 130^{\circ} 5^{\prime} \mathrm{W}$ or the eastern Ifremer contract area) and a western (W site, located at $9^{\circ} 33^{\prime} \mathrm{N}, 150^{\circ} 0.5^{\prime} \mathrm{W}$, the western Ifremer contract area) sites. In this study the authors found that in the eastern site Lumbrineridae and Amphinomidae were the most dominant families. The central and western sites ( $E$ and $W$ ) instead showed an 
assemblage dominated by Spionidae, Cirratulidae, Syllidae and Paraonidae, with Spionidae displaying relative abundances comparable to the values observed in the present study. In our studies Amphinomidae were not recorded and Lumbrineridae were found in very low relative abundances (3\%). As suggested by Smith et al. (2008b) and supported by Bonifácio et al. (2020), the dominance of jawed carnivores such as lumbrinerids, amphinomids and sigalionids in the eastern side reinforces the expected higher surface productivity of this region of the CCFZ, for the development of higher trophic levels needs a relatively high abundance of prey. The GSR contract area is composed of an i) eastern sub-area, B6, of which the B6S02 site was sampled by De Smet et al. (2017) during the GSRNOD15A sampling campaign, ii) a central sub-area, B4 of which B4S03 was sampled during both GSRNOD15A and the current study GSRNOD17 cruise, and iii) an western sub-area B2, which was sampled in a non-quantitative and replicated fashion during GSRNOD14, and for which no macrofauna data is available. In De Smet et al. (2017) the Polychaeta family composition displayed a significantly higher presence of Lumbrineridae at the eastern-most site $\mathrm{B} 6 \mathrm{~S} 02$ compared to the other two B4 investigated stations where the family was only represented in two out of nine box-cores and in very low relative abundances. In the $\mathrm{B} 6 \mathrm{SO} 2 \mathrm{2}$ site the family was found in each sample and it comprised $20 \%$ of the assemblage. From this evidence we can assume that the polychaete diversity patterns in the sub-areas of the GSR contract area follow the previously described east-west gradient in productivity (Smith et al., 2008a; Volz et al., 2018); the site under current investigation (B4S03) is part of the central zone of the CCFZ where higher trophic levels can be expected to occur infrequently because of the low overall food availability and this is reflected in the dominance of polychaete deposit feeder families (e.g. Spionids) and the virtual absence of predator families observed in the current study.

During GSRNOD15A De Smet et al., (2017) recorded a total of 53 polychaete taxa (at genus and species level) for B4 (B4S03 and B4N01 sites) and B6 (B6S02 station) GSR contract sub-areas, of which only 26\% of the taxa were shared between the three stations. When the authors computed the asymptotic diversity $S_{\text {Chao1 }}$ the result pointed at a total of 77 taxa to be found across the different sites with an increasing number of samples, based on an overall sampling effort of 12 box cores. During the current study, we found 46 species from a total of ten box cores at the B4S03 site. It would therefore seem that the Chao1 non-parametric diversity estimator underestimated the potential diversity of the GSR sites during the 
work of De Smet et al. (2017), because during the present study we found a total of 46 species and an estimated $\mathrm{S}_{\mathrm{Chao} 1}$ of 74.8 species for the sole B4S03 site. In our study, and in that of other authors (Bonifácio et al., 2020), the number of polychaete singletons did not decrease with the increasing number of box-corers sampled, as $52 \%$ of the polychaete species found across all box-cores were singletons. Further, during this study polychaete morphospecies distribution within B4S03 and across the investigated stations (Figure 4 b) showed a higher degree of uniqueness (15 unique species out of 46 ) at Nodrich_A which is the northern-most and most distant station relative to the other two southern stations. Nonetheless, Nodfree and Nodrich_B are both located at the south of B4S03 and only $3 \mathrm{~km}$ apart from each other and they showed the highest number of shared morphospecies (7 out of 46 ). This observation may point at a higher dispersal potential across shorter distances for polychaete larvae at these depths. Previous studies showed that in comparison to isopods, polychaetes indeed have a slightly better potential for dispersal (Janssen et al., 2015, 2019). Bonifácio et al. (2020) estimated a polychaete diversity that could range from 498 species (estimated by Chao1 estimator) to 240,000 species (based on species turnover rates) for the 6 million $\mathrm{km}^{2}$ of the CCFZ region. Ongoing and future baseline studies in the CCFZ nodule fields need to focus on gathering more species distributional data for dominant taxa such as Polychaeta to be able to estimate and hence mitigate the effects that potential habitat fragmentation resulting from the nodule harvesting activities could have on the distribution and dispersal of species.

\section{2 .3}

\section{Tanaidacea}

There are few studies dedicated to tanaidacean diversity and describing their community in the CCFZ. In the analysis of macrofauna assemblages in DOMES site $A$ and site $C$ (ECHO1), only six tanaidacean families were recorded: Leptognathiidae, Pseudotanaidae, Agathotanaidae, Anarthruridae, Neotanaidae and Whitellegidae (Wilson, 1987). The 77 species of Tanaidacea recorded by Wilson (1987; 2017) (Wilson, 1987, 2017)could be classified to at least nine families (Agathotanaidae, Akanthophoreidae, Apseudidae, Colletteidae, Leptognathiidae, Neotanaidae, Pseudotanaidae, Paranarthrurellidae and Typhlotanaidae). Błażewicz et al. (2019) in a study that covered the contract areas of BGR, IOM, GSR, Ifremer and the Area of Particular Environmental Interest APEI\#3, recorded a high tanadacean diversity comparable to the present study. The unique character of each area was proved based on molecular data for the only 
601

602

603

604

605

606

607

608

609

610

611

612

613

614

615

616

617

618

619

620

621

622

623

624

625

tanaidacean family (Pseudotanaidae) that was present at each of the mentioned areas (Jakiel et al., 2019). Further, Błażewicz et al. (2019) reported a total of 22 species from 5 box-corers samples taken at GSR B6S02 site at depths around $4500 \mathrm{~m}$. The authors stated that most species were unique to one area and that $47 \%$ were singletons. A species list was not provided in the work hence comparisons with the current study on B4S03 cannot be made at the moment. A high degree of licence area-specific morphospecies distribution was also detected by Błażewicz et al. (2019) when comparing far distant contract areas within the CCFZ nodule fields. In our study we identified one morphospecies which was assigned to the genus Neotanais (Neotanaidae family, Neotanais sp. \#161), recorded only once (singleton) and which was unique to Nodfree station. The genus Neotanais has been sampled by other authors during the JPIO cruise in the CCFZ and it displayed very high genetic diversity with 4 individuals all representing four new species (Magda Błażewicz, personal communication). Moreover, during this study the specialist taxonomist found four new genera and a potentially new family.

Tanaidacea are among the least known deep-sea taxa. Their densities in the deep sea are thought to be under-estimated and their importance in the macrobenthic community seems to be comparable to that of isopods or amphipods (Błażewicz-Paszkowycz et al., 2012; Jakiel et al., 2019). For the greater part free-living tanaids are known to live into self-constructed tubes or buried in sediments and to display a brooding reproduction type (Jakiel et al., 2019 and references therein). Characterised by the lack of larval phase and in light of their low mobility, they are known to have a low dispersal capacity, although active stages and opportunist benthopelagic forms such as the "swimming male" of Leptoghnathia sp., Kudinova-Pasternak 1970, have been mentioned as likely early colonisers of deep-sea disturbed sediments at great depths (Bird and Holdich, 1989; Błażewicz-Paszkowycz et al., 2014) or important element sustaining the population connectivity in the scarcely distributed and infrequent deep-sea population. The high diversity measured for this taxon at $\mathrm{B} 4 \mathrm{SO} 3$ and a substantial contribution of individuals identified only to superfamily level (Paratanaoidea/family incertae sedis), stay in line with a high diversity of the tanaidacean recorded in the deep-sea (Błażewicz-Paszkowycz et al., 2012; Poore et al., 2015) and it is in line with the typical high diversity recorded in the deep sea for other taxa (Rex and Etter 2010) and general underestimation of the small marine peracarids (Appeltans et al., 2012). Nonetheless the high number of singletons can again be a sign of under-sampling, a risk for diversity under-estimation and the low den- 
sities and high patchiness in the distribution of these organisms can instead over-estimate the level of specificity and endemism of the identified morphospecies.

The analysis of diversity estimation for the three main taxa highlighted a common trend: a high number of singletons not declining with an increasing number of samples. The use of the Chao1 estimator, which takes in consideration the number of singletons and doubletons, may not be fit for highly diverse ecosystems such as the deep sea, for this asymptotic estimator assumes that the number of singletons will decrease with increasing number of samples (Melo, 2004). In this study, for isopods as for the other two taxa, the number of singletons was $>50 \%$, with one in two individuals representing a new species which would be encountered only once across all samples. Very high levels of singletons are a characteristic of most deep-sea ecosystems (excl. chemosynthetic ecosystems), where rare and common species contribute to an equal $25 \%$ of all singletons (Rex and Etter, 2010) and one on three macrofauna organisms in a sampling area is a singleton (Gage, 2004). Coddington et al. (2009) recorded, for the spider population of a large area of rain forest, a very high number of singletons (26\%) during an intensive survey. The authors concluded that this result was most likely due to under-sampling in a highly diverse ecosystem, generating negative biases for diversity estimators. Under-sampling can hence cause an underestimation of diversity, but at the same time it can overestimate the level of endemism and hence produce an illusionary narrowness of the effective distribution range of species, as $1 / 3$ of the species are potentially singletons and would then be considered endemic to a specific area.

The environmental impact assessment (EIA) outlined by the International Seabed Authority is a prerequisite to Deep-Sea Mining activities in areas beyond national jurisdiction such as the CCFZ. The requirements for the EIA are, righteously, particularly detailed and demanding in terms of in-depth information on the baseline status of the local ecosystem and of the potential effects nodule harvesting activities may have on these remote biomes of the Earth's ocean floor. The deep-sea nodule fields of the CCFZ represent a yet very understudied ecosystem that spans for about 6 million square kilometres at abyssal depths in the North Central Pacific Ocean and which are logistically impervious to investigate thorough- 
ly. From the yet limited information gathered in the present study and with the knowledge gathered from other studies in the area, it is clear that the local diversity is most likely highly underestimated by each of the sampling campaigns that have been carried out to date in the region. In Figure 6 we find the rarefaction/extrapolation (R/E) curves (with 95\% confidence intervals) for the different taxa $(a, b)$ and the related sample coverage $(S C ; C, d)$ for species and family level. For most taxa the SC is relatively high at the family level, with Tanaidacea showing a value approaching SC $=1$, followed by the Isopoda and the Polychaeta. At the species level the extrapolated $S_{\text {est }}$ shows how the Polychaeta require a larger sampling compared to the Tanaidacea and Isopoda and that no asymptote will be reached when a total of 200 polychaete individuals will have been sampled at B4S03 (Figure 6 c). The estimation for necessary additional sampling effort in order to cover the complete (estimated) biodiversity reached as many as 126 individuals for Isopoda, 745 individuals for Polychaeta and 575 individuals for Tanaidacea. Further, to record $100 \%(g=1)$ of the estimated diversity (which can be assumed being under-estimated for each of the three taxa in light of the high percentage of singletons), we would need five times the sampling effort for Isopoda, eight times for Polychaeta and ten times for Tanaidacea (Table 4). To make sure the most vulnerable taxa are sufficiently represented, which are the ones with the lowest dispersal capacity such as the Asellota Isopoda or the highly diverse Tanaidacea, a five- to ten-fold sampling effort in the B4S03 site is required. In the case we would achieve the minimum required sampling to estimate the total diversity of the Asellota as per this investigation, we would need to sample five times the original sampling area or collect a total of 50 box-cores. In this case we would be able to record the Isopoda $\mathrm{S}_{\text {Chao1 }}(\mathrm{g}=1)$ diversity, whereas for Polychaeta and Tanaidacea we would reach an estimated $\mathrm{g} \geq 0.95$.

Therefore, a more comprehensive sampling strategy is needed to estimate the full diversity of sites such as $\mathrm{B} 4 \mathrm{SO3}$, though a moderate increase in sampling may be sufficient to characterize higher taxon level community structure.

To fully characterize local diversity to the lowest taxonomic level, future sampling campaigns would ideally need to carry out an improved comprehensive type of sampling design and focus on B4SO3 and/or B6S02 (GSR sites with most information available) to unravel the local diversity coupling molecular tools 
683

684

685

686

687

688

689

690

691

692

693

694

695

696

697

698

699

700

701

702

703

704

705

706

707

sity to each sites' habitat/environmental characteristics in order to identify potentially important drivers and to finally be able to unravel connectivity patterns of selected taxa with different dispersal potential between the two sites.

\section{Conclusions}

The macrofauna of the B4S03 site within the GSR contract area is highly diverse. The presence of nodules did not affect either the soft sediment characteristics or the biological assemblage in an obvious way. The densities of the local macrofauna or the diversity of Isopoda, Polychaeta and Tanaidacea did not significantly differ between the investigated stations, nor did the overall macrofauna assemblage structure with polychaetes dominating the abundances followed by tanaids and isopods. The high number of singletons encountered during the study may be a sign of under-sampling and a risk for diversity underestimation at the investigated sites. In light of the requirements for the Environmental Impact Assessment outlined by the International Seabed Authority, contractors need to be able to properly estimate the local diversity to then mitigate the effects that potential habitat fragmentation resulting from the harvesting activities could have on the local survival of species. The understanding of diversity patterns at the different spatial scales (from local to regional) is paramount to the proper management of deep-sea mining in the CCFZ region. We recommend a more extensive sampling design but also complementary analytical effort with the combination of molecular tools with taxonomical expertise to fully characterize biodiversity (including cryptic species) and to identify connectivity patterns crucial for management of deep-sea mining activities.

\section{Authors contribution}

Francesca Pasotti analysed and interpreted the data, produced and organised the results and wrote the manuscript. Lisa Mevenkamp helped with the analysis and data interpretation, carried out most of the after-cruise sample processing and did part of the lower-taxon identification with the help of the expert taxonomists. Ellen Pape coordinated the sampling design, helped with the data analysis, the interpretation of the results and the review of the manuscript. Lidia Lins and Bart De Smet carried out the 
GSRNOD17 sampling and helped in reviewing the present manuscript. Nene Lefaible helped in reviewing the manuscript and processed part of the macrofauna samples. Blażewicz-Paszkowycz identified the Tanaidacea up to lower taxon level, Torben Riehl the Isopoda, and Paulo Bonifácio identified the Polychaeta. All the expert taxonomists helped in the interpretation of the data and the review of the manuscript. Ann Vanreusel is the project leader and helped in the sampling design, the data analyses and interpretation and the writing of the manuscript.

\section{Acknowledgments}

The authors wish to extend their gratitude and appreciation to the captain and (scientific) crew of the RV "Topaz Captain" as well as OFG for the help on board during the GSRNOD17 cruise. We also wish to acknowledge the exploration manager and chief scientist François Charlet (GSR). The help of Céline Taymans (GSR) and Tania Nara Bezerra (UGent) with onboard sample processing was greatly appreciated. Further, we wish to thank Hannah Wright who helped with the identification of macrofauna to higher-taxon level. Bruno Vlaeminck and Bart Beuselinck are acknowledged for their help with the environmental variable analysis. This investigation was part of the environmental baseline survey carried out by GSR within its contract area and it was supported by a service arrangement between Global Sea Mineral Resources N.V. and Ghent University.

\section{References}

Amon, D. J., Ziegler, A. F., Dahlgren, T. G., Glover, A. G., Goineau, A., Gooday, A. J., Wiklund, H., et al. 2016. Insights into the abundance and diversity of abyssal megafauna in a polymetallic-nodule region in the eastern Clarion-Clipperton Zone. Scientific Reports, 6: 30492.

Amon, D. J., Ziegler, A. F., Drazen, J. C., Grischenko, A. V., Leitner, A. B., Lindsay, D. J., Voight, J. R., et al. 2017. Megafauna of the UKSRL exploration contract area and eastern Clarion-Clipperton Zone in the Pacific Ocean: Annelida, Arthropoda, Bryozoa, Chordata, Ctenophora, Mollusca. Biodiversity Data Journal. https://www.ncbi.nIm.nih.gov/pmc/articles/PMC5565845/ (Accessed 26 September 2018). 
733

734

Appeltans, W., Ahyong, S. T., Anderson, G., Angel, M. V., Artois, T., Bailly, N., Bamber, R., et al. 2012. The Magnitude of Global Marine Species Diversity. Current Biology, 22: 2189-2202.

Arndt, S., Jørgensen, B. B., LaRowe, D. E., Middelburg, J. J., Pancost, R. D., and Regnier, P. 2013. Quantifying the degradation of organic matter in marine sediments: a review and synthesis. Earth-Science Reviews, 123: 53-86.

Balaram, V. 2019. Rare earth elements: A review of applications, occurrence, exploration, analysis, recycling, and environmental impact. Geoscience Frontiers, 10: 1285-1303.

Behrenfeld, M. J., and Falkowski, P. G. 1997. Photosynthetic rates derived from satellite-based chlorophyll concentration. Limnology and Oceanography, 42: 1-20.

Bird, G. J., and Holdich, D. M. 1989. Recolonisation of artificial sediments in the deep bay of Biscay by Tanaidaceans (Crustacea: Peracarida), with a description of a new species of Pseudotanais. Journal of Marine Biological Association U.K., 69: 307-317.

Błażewicz, M., Jóźwiak, P., Menot, L., and Pabis, K. 2019. High species richness and unique composition of the tanaidacean communities associated with five areas in the Pacific polymetallic nodule fields. Progress in Oceanography, 176: 102141.

Błażewicz-Paszkowycz, M., Bamber, R., and Anderson, G. 2012. Diversity of Tanaidacea (Crustacea, Peracarida) in the World's ocean: how far have we come? Plos One, 7.

Błażewicz-Paszkowycz, M., Jennings, R. M., Jeskulke, K., and Brix, S. 2014. Discovery of swimming males of Paratanoidea (Tanaidacea). Polish Polar Research, 35: 415-453.

Bober, J., Brandt, A., Frutos, I., and Schwentner, M. 2019. Diversity and distribution of Ischnomesidae (Crustacea: Isopoda: Asellota) along the Kuril-Kamchatka Trench - A genetic perspective. Progress in Oceanography, 178: 102174.

Bonifácio, P., and Menot, L. 2019. New genera and species from the Equatorial Pacific provide phylogenetic insights into deep-sea Polynoidae (Annelida). Zoological Journal of the Linnean Society, 185: 555-635. 
Bonifácio, P., Martínez Arbizu, P., and Menot, L. 2020. Alpha and beta diversity patterns of polychaete assemblages across the nodule province of the eastern Clarion-Clipperton Fracture Zone (equatorial Pacific). Biogeosciences, 17: 865-886. Copernicus GmbH.

Burns, R. G., and Burns, V. M. 1977. The mineralogy and crystal chemistry of deep-sea manganese nodules, a polymetallic resource of the twenty-first century. Philosophical Transactions of the Royal Society of London, 286: 283-301.

Bussau, C. 1993. Taxonomische und ökologische untersuchungen an Nematoden des Peru-Beckens. na.

Chao, A., Colwell, R. K., Lin, C.-W., and Gotelli, N. J. 2009. Sufficient sampling for asymptotic minimum species richness estimators. Ecology, 90: 1125-1133.

Chao, A., Gotelli, N. J., Hsieh, T. C., Sander, E. L., Ma, K. H., Colwell, R. K., and Ellison, A. M. 2014. Rarefaction and extrapolation with Hill numbers: a framework for sampling and estimation in species diversity studies. Ecological Monographs, 84: 45-67.

Christodoulou, M., O'Hara, T. D., Hugall, A. F., and Arbizu, P. M. 2019. Dark ophiuroid biodiversity in a prospective abyssal mine field. Current Biology, 29: 3909-3912.

Coddington, J. A., Agnarsson, I., Miller, J. A., Kuntner, M., and Hormiga, G. 2009. Undersampling bias: the null hypothesis for singleton species in tropical arthropod surveys. Journal of Animal Ecology, 78: $573-584$.

De Smet, B., Pape, E., Riehl, T., Bonifácio, P., Colson, L., and Vanreusel, A. 2017. The Community Structure of Deep-Sea Macrofauna Associated with Polymetallic Nodules in the Eastern Part of the ClarionClipperton Fracture Zone. Frontiers in Marine Science, 4. http://journal.frontiersin.org/article/10.3389/fmars.2017.00103/abstract (Accessed 11 April 2017).

Dover, C. L. V., Ardron, J. A., Escobar, E., Gianni, M., Gjerde, K. M., Jaeckel, A., Jones, D. O. B., et al. 2017. Biodiversity loss from deep-sea mining. Nature Geoscience, 10: 464-465.

Elsner, N. O., Malyutina, M. V., Golovan, O. A., Brenke, N., Riehl, T., and Brandt, A. 2015. Deep down: isopod biodiversity of the Kuril-Kamchatka abyssal area including a comparison with data of previous expeditions of the RV Vityaz. Deep-Sea Research II, 111: 210-219. 
Gage, J. D. 2004. Diversity in deep-sea benthic macrofauna: The importance of local ecology, the larger scale, history and the Antarctic. Deep-Sea Research Part II: Topical Studies in Oceanography, 51: 1689-1708.

Gehlenborg, N. 2019. UpSetR: A More Scalable Alternative to Venn and Euler Diagrams for Visualizing Intersecting Sets. https://CRAN.R-project.org/package=UpSetR.

Gheerardyn, H., and George, K. H. 2019. Description of a new species of Neoargestes Drzycimski, 1967 (Copepoda, Harpacticoida, Argestidae) from the Clarion Clipperton Fracture Zone (Pacific Ocean), with remarks on the systematics of the genus. Marine Biodiversity. https://doi.org/10.1007/s12526-019-00951-1 (Accessed 6 May 2019).

Giere, O. 2009. Meiobenthology: the microscopic motile fauna of aquatic sediments. Springer-Verlag, Berlin. 527 pp. file:///D:/Elpape/My Documents/Ellen.Data/PDF/Giere_Meiobenthology_20092871546624/Giere_Meiobenthology_2009.pdf.

Glover, A. G., and Smith, C. R. 2003. The deep-sea floor ecosystem: current status and prospects of anthropogenic change by the year 2025. Environmental Conservation, null: 219-241.

Golovan, O. A., Błażewicz, M., Brandt, A., Jażdżewska, A. M., Jóźwiak, P., Lavrenteva, A. V., Malyutina, M. V., et al. 2019. Diversity and distribution of peracarid crustaceans (Malacostraca) from the abyss adjacent to the Kuril-Kamchatka Trench. Marine Biodiversity, 49: 1343-1360.

Gooday, A., and Rathburn, A. 1999. Temporal variability in living deep-sea foraminifera: a review. Earth Science Reviews, 46: 187-212.

Gooday, A. 2002. Biological responses to seasonally varying fluxes of organic matter to the ocean floor: a review. Journal of Oceanography, 58: 305-332.

Goslee, S., and Urban, D. 2020. ecodist: Dissimilarity-Based Functions for Ecological Analysis. https://CRAN.R-project.org/package=ecodist.

Hervé, M. 2020. RVAideMemoire: Testing and Plotting Procedures for Biostatistics. https://CRAN.Rproject.org/package=RVAideMemoire . 
Hessler, R. R., and Jumars, P. A. 1974. Abyssal community analysis from replicate box cores in the central North Pacific. Deep Sea Research and Oceanographic Abstracts, 21: 185-209.

Hsieh, T. C., Ma, K. H., and Chao, A. 2016. iNEXT: an R package for rarefaction and extrapolation of species diversity (Hill numbers). Methods in Ecology and Evolution, 7: 1451-1456.

Hsieh, T. C., and Chao, A. 2019. Package iNEXT 2.0.19: interpolation and extrapolation of species diversity. http://chao.stat.nthu.edu.tw/blog/software-download/.

Hurlbert, S. H. 1971. The nonconcept of species diversity: a critique and alternative parameters. Ecology, 52: $577-586$.

Jakiel, A., Palero, F., and Błażewicz, M. 2019. Deep ocean seascape and Pseudotanaidae (Crustacea: Tanaidacea) diversity at the Clarion-Clipperton Fracture Zone. Scientific Reports, 9: 1-49.

Janssen, A., Kaiser, S., Meißner, K., Brenke, N., Menot, L., and Martínez Arbizu, P. 2015. A Reverse Taxonomic Approach to Assess Macrofaunal Distribution Patterns in Abyssal Pacific Polymetallic Nodule Fields. PLoS ONE, 10: e0117790.

Janssen, A., Stuckas, H., Vink, A., and Arbizu, P. M. 2019. Biogeography and population structure of predominant macrofaunal taxa (Annelida and Isopoda) in abyssal polymetallic nodule fields: implications for conservation and management. Marine Biodiversity. https://doi.org/10.1007/s12526019-00997-1 (Accessed 2 October 2019).

Jóźwiak, P., Pabis, K., Brandt, A., and Błażewicz, M. 2020. Epibenthic sled versus giant box corer - Comparison of sampling gears for tanaidacean species richness assessment in the abyssal benthic ecosystem. Progress in Oceanography, 181: 102255.

Juan, C., Van Rooij, D., and De Bruycker, W. 2018. An assessment of bottom current controlled sedimentation in Pacific Ocean abyssal environments. Marine Geology, 403: 20-33.

Kaiser, S., Barnes, D. K. A., and Brandt, A. 2007. Slope and deep-sea abundance across scales: Southern Ocean isopods show how complex the deep sea can be. Deep-Sea Research II, 54: 1776-1789. 
Kersken, D., Janussen, D., and Arbizu, P. M. 2019. Deep-sea glass sponges (Hexactinellida) from polymetallic nodule fields in the Clarion-Clipperton Fracture Zone (CCFZ), northeastern Pacific: Part II-Hexasterophora. Marine Biodiversity, 49: 947-987.

Khripounoff, A., Caprais, J. C., Crassous, P., and Etoubleau, J. 2006. Geochemical and biological recovery of the disturbed seafloor in polymetallic nodule fields of the Clipperton-Clarion Fracture Zone (CCFZ) at 5,000-m depth. Limnology and Oceanography, 51: 2033-2041.

Lutz, M. J., Caldeira, K., Dunbar, R. B., and Behrenfeld, M. J. 2007. Seasonal rhytms of net primary production and particulate organic carbon flux describe biological pump efficiency in the global ocean. Journal of Geophysical Research, 112.

Maybury, C. 1996. Crevice Foraminifera from abyssal South East Pacific manganese nodules. In Microfossils and Oceanic Environments. Ed. by Moguilevsky.

Melo, A. S. 2004. A critique of the use of jackknife and related non-parametric techniques to estimate species richness. Community Ecology, 5: 149-157.

Meyer-Löbbecke, A., Brandt, A., and Brix, S. 2014. Diversity and abundance of deep-sea Isopoda along the Southern Polar Front: Results from the SYSTCO I and II expeditions. Deep Sea Research Part II: Topical Studies in Oceanography, 108: 76-84.

Michael J. Rex, and Ron J. Etter. 2010. Deep-sea Biodiversity: Pattern and Scale. Harvard University Press, Cambridge, Massachussets. 354 pp.

Miljutin, D., Miljutina, M., and Messié, M. 2015. Changes in abundance and community structure of nematodes from the abyssal polymetallic nodule field, Tropical Northeast Pacific. Deep Sea Research Part I: Oceanographic Research Papers, 106: 126-135.

Murray, J., and Renard, Rev. A. F. 1891. Report on deep-sea deposits based on the specimens collected during the voyage of the H.M.S. Challenger in the years 1872 to 1876 . Order of her Majesty Office.

Oksanen, J., Blanchet, F. G., Friendly, M., Kindt, R., Legendre, P., McGlinn, D., Minchin, P. R., et al. 2019. vegan: Community Ecology Package. https://CRAN.R-project.org/package=vegan. 
Pape, E., Bezerra, T. N., Gheerardyn, H., Buydens, M., Kieswetter, A., and Vanreusel, A. In prep. Are polymetallic nodules important for deep-sea meiofauna?

Pape, E., De Smet, B., Bogaert, K., and Vanreusel, A. 2016. Biological and environmental report on the 2014 and 2015 expeditions in the GSR license area. Marine Biology Research Group, Ghent University, Ghent, Belgium.

Paul, A. Z., and Hecker, B. 1979. Abyssal Community Structure of the Benthic Infauna of the Eastern Equatorial Pacific: DOMES Sites A, B, and C. In Marine Geology and Oceanography of the Pacific Manganese Nodule Province, pp. 287-308. Ed. by J. L. Bischoff and D. Z. Piper. Springer US. http://link.springer.com/chapter/10.1007/978-1-4684-3518-4_8 (Accessed 8 October 2014).

Pennington, J. T., Mahoney, K. L., Kuwahara, V. S., Kolber, D. D., Calienes, R., and Chavez, F. P. 2006. Primary production in the eastern tropical Pacific: A review. Progress in Oceanography, 69: 285-317.

Petersen, S., Krätschell, A., Augustin, N., Jamieson, J., Hein, J. R., and Hannington, M. D. 2016. News from the seabed - Geological characteristics and resource potential of deep-sea mineral resources. Marine Policy, 70: 175-187.

Poore, G. C. B., Avery, L., Błażewicz-Paszkowycz, M., Browne, J., Bruce, N. L., Gerken, S., Glasby, C., et al. 2015. Invertebrate diversity of the unexplored marine western margin of Australia: taxonomy and implications for global biodiversity. Marine Biodiversity, 45: 271-286.

R Core Team. 2020. R: A Language and Environment for Statistical Computing. R Foundation for Statistical Computing, Vienna, Austria. https://www.R-project.org/.

Rex, M. A., and Etter, R. J. 2010. Deep-Sea Biodiversity: Pattern and Scale. Harvard University Press. 388 pp.

Riehl, T., Wilson, G. D. F., and Malyutina, M. V. 2014. Urstylidae - a new family of abyssal isopods (Crustacea: Asellota) and its phylogenetic implications. Zoological Journal of the Linnean Society, 170: 245-296. 
Riehl, T., and De Smet, B. (n.d.). Macrostylis metallicola spec. nov. - An isopod with geographically clustered genetic variability from a polymetallic-nodule area in the Clarion-Clipperton Fracture Zone. in press.

Sanders, H. 1968. Marine benthic diversity: a comparative study. The American Naturalist, 102: 243.

Smith, C., and Demopoulos, W. R. 2003. The deep Pacific Ocean floor. In Ecosystems of the Deep Oceans, pp. 179-218. Elsevier Science, Amsterdam.

Smith, C. R., Hoover, D. J., Doan, S. E., Pope, R. H., Demaster, D. J., Dobbs, F. C., and Altabet, M. A. 1996. Phytodetritus at the abyssal seafloor across $10^{\circ}$ of latitude in the central equatorial Pacific. Deep Sea Research Part II: Topical Studies in Oceanography, 43: 1309-1338.

Smith, C. R., Berelson, W., Demaster, D. J., Dobbs, F. C., Hammond, D., Hoover, D. J., Pope, R. H., et al. 1997. Latitudinal variations in benthic processes in the abyssal equatorial Pacific: control by biogenic particle flux. Deep Sea Research Part II: Topical Studies in Oceanography, 44: 2295-2317.

Smith, C. R., Paterson, G., Lambshead, J., Glover, A., Rogers, A., Gooday, A., Kitazato, H., et al. 2008a. Biodiversity, species ranges, and gene flow in the abyssal Pacific nodule province: predicting and managing the impacts of deep seabed mining. Monograph, ISA technical study, 3. International Seabed Authority. http://eprints.soton.ac.uk/63301/ (Accessed 3 July 2014).

Smith, C. R., De Leo, F. C., Bernardino, A. F., Sweetman, A. K., and Martinez Arbizu, P. 2008b. Abyssal food limitation, ecosystem structure and climate change. Trends in Ecology and Evolution, 23: 518528.

Smith, K. L. Jr., Ruhl, H. A., Huffard, C. L., Messié, M., and Kahru, M. 2018. Episodic organic carbon fluxes from surface ocean to abyssal depths during long-term monitoring in NE Pacific. PNAS, 115: $12235-12240$.

Sweetman, A. K., Smith, C. R., Shulse, C. N., Maillot, B., Lindh, M., Church, M. J., Meyer, K. S., et al. 2019. Key role of bacteria in the short-term cycling of carbon at the abyssal seafloor in a low particulate organic carbon flux region of the eastern Pacific Ocean. Limnology and Oceanography, 0. https://aslopubs.onlinelibrary.wiley.com/doi/abs/10.1002/Ino.11069 (Accessed 6 December 2018). 
Thiel, H., Schriever, G., Bussau, C., and Borowski, C. 1993. Manganese nodule crevice fauna. Deep Sea Research Part I: Oceanographic Research Papers, 40: 419-423.

Thistle, D., and Wilson, G. D. F. 1987. A hydrodynamically modified, abyssal isopod fauna. Deep Sea Research Part A. Oceanographic Research Papers, 34: 73-87.

Thistle, D., and Wilson, G. D. F. 1996. Is the HEBBLE isopod fauna hydrodynamically modified? A second test. Deep Sea Research Part I: Oceanographic Research Papers, 43: 545-554.

Vanreusel, A., Hilario, A., Ribeiro, P. A., Menot, L., and Arbizu, P. M. 2016. Threatened by mining, polymetallic nodules are required to preserve abyssal epifauna. Scientific Reports, 6: 26808.

Vavrek, M. J. 2020. fossil: Palaeoecological and Palaeogeographical Analysis Tools. https://CRAN.Rproject.org/package $=$ fossil.

Veillette, J., Sarrazin, J., Gooday, A. J., Galéron, J., Caprais, J.-C., Vangriesheim, A., Étoubleau, J., et al. 2007a. Ferromanganese nodule fauna in the Tropical North Pacific Ocean: Species richness, faunal cover and spatial distribution. Deep Sea Research Part I: Oceanographic Research Papers, 54: $1912-1935$.

Veillette, J., Juniper, S. K., Gooday, A. J., and Sarrazin, J. 2007b. Influence of surface texture and microhabitat heterogeneity in structuring nodule faunal communities. Deep Sea Research Part I: Oceanographic Research Papers, 54: 1936-1943.

Volz, J. B., Mogollón, J. M., Geibert, W., Arbizu, P. M., Koschinsky, A., and Kasten, S. 2018. Natural spatial variability of depositional conditions, biogeochemical processes and element fluxes in sediments of the eastern Clarion-Clipperton Zone, Pacific Ocean. Deep Sea Research Part I: Oceanographic Research Papers, 140: 159-172.

Wiklund, H., Neal, L., Glover, A. G., Drennan, R., Rabone, M., and Dahlgren, T. G. 2019. Abyssal fauna of polymetallic nodule exploration areas, eastern Clarion-Clipperton Zone, central Pacific Ocean: Annelida: Capitellidae, Opheliidae, Scalibregmatidae, and Travisiidae. ZooKeys, 883: 1-82.

Wilson, G. D. F. 1987. Crustacean communities of the manganese nodule province (DOMES site A compared with DOMES site C). Report for the National Oceanic and Atmospheric Administration Of- 
fice of the Ocean Coastal Resource Management (Ocean, Minerals and Energy). On Contract Na84-Abh-0300: 40.

937 Wilson, G. D. F. 2008. Local and regional species diversity of benthic Isopoda (Crustacea) in the deep Gulf of Mexico. Deep-Sea Research II, 55: 2634-2649.

939 Wilson, G. D. F. 2017. Macrofauna abundance, species diversity and turnover at three sites in the Clipperton-Clarion Fracture Zone. Marine Biodiversity, 47: 323-347.

\section{Figures}

Figure 1. Map of the Clarion Clipperton Fracture Zone polymetallic nodule fields with represented in green 950 the GSR contract area with the three sub-areas (B2, B4, B6) and a magnification of the sampling stations within the B4S03 site. Depth range: 4420 m (black) - 4591 m (white). 


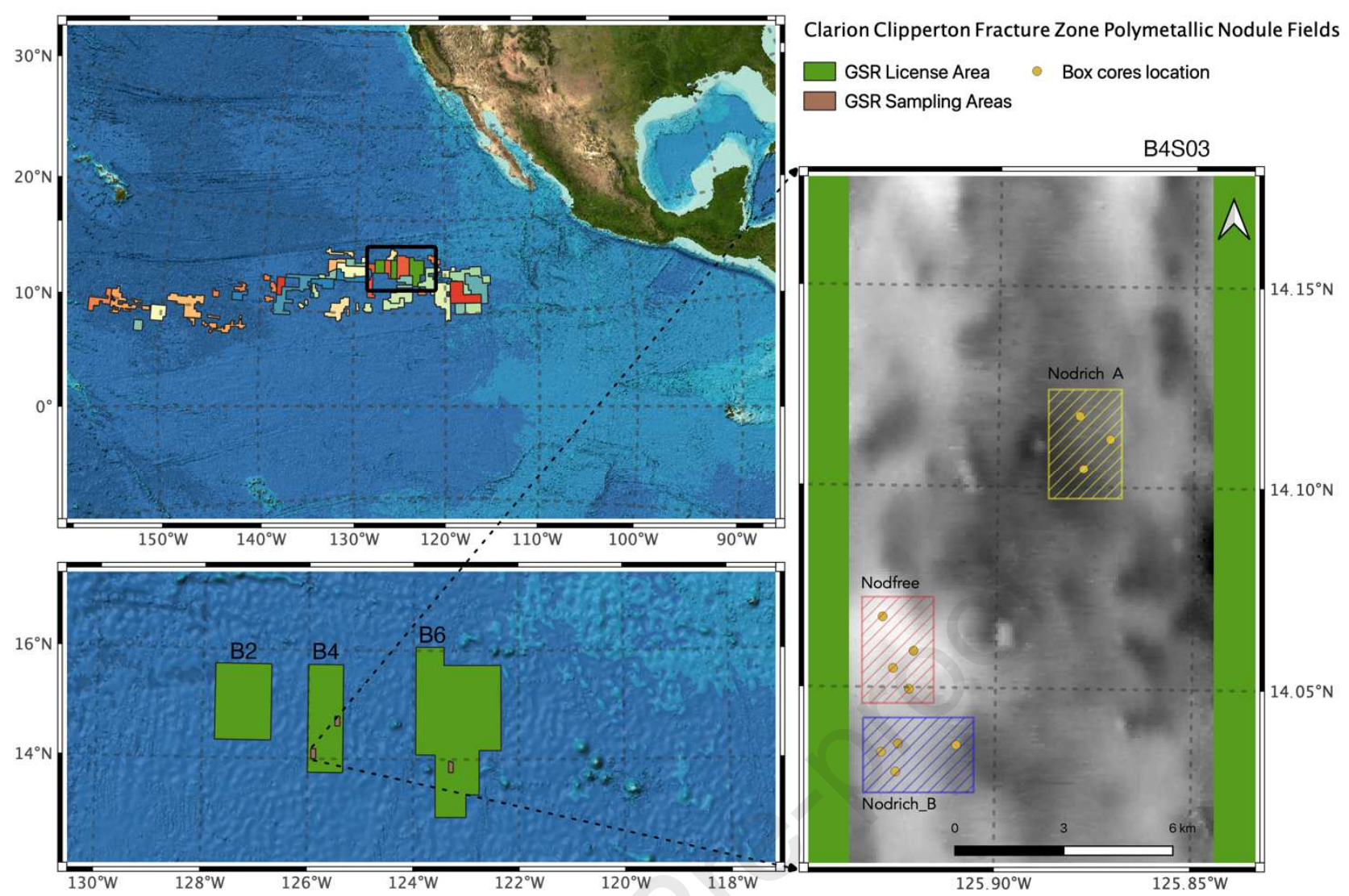

Figure 2. Principal component analysis (PCA) of the sediment environmental variables (including pigments) for the $0-5 \mathrm{~cm}$ layer for the three stations (Nodfree in red, Nodrich_A in yellow, Nodrich_B in blue), based on Euclidean distance similarities on the normalised data. The vectors represent the environmental variables and the two axes represent the two most important principal components (PC1 and PC2) and the percentage of variability they explain is reported. The ellipses represent the 0.95 confidence interval of the data distribution of each station around a centroid. 


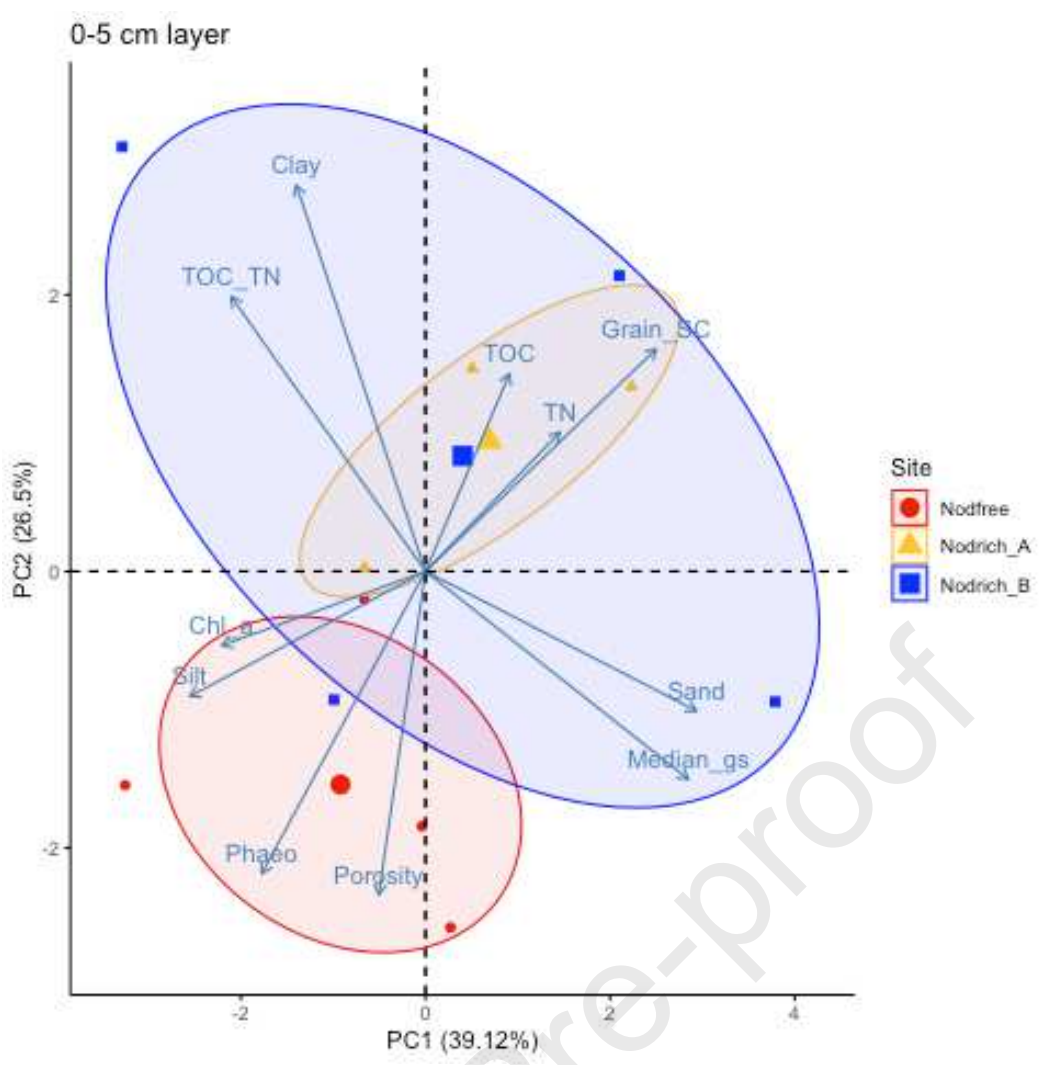

991 Figure 3. Monthly-averaged net primary production (NPP) in the B4S03 site for the period June 2015 - June 2017. The blue vertical band represents the timing of the previous GSRNOD15A cruise event (SeptemberOctober 2015) whereas the orange vertical band refers to the present study GSRNOD17 sampling campaign 994 of May-June 2017. 

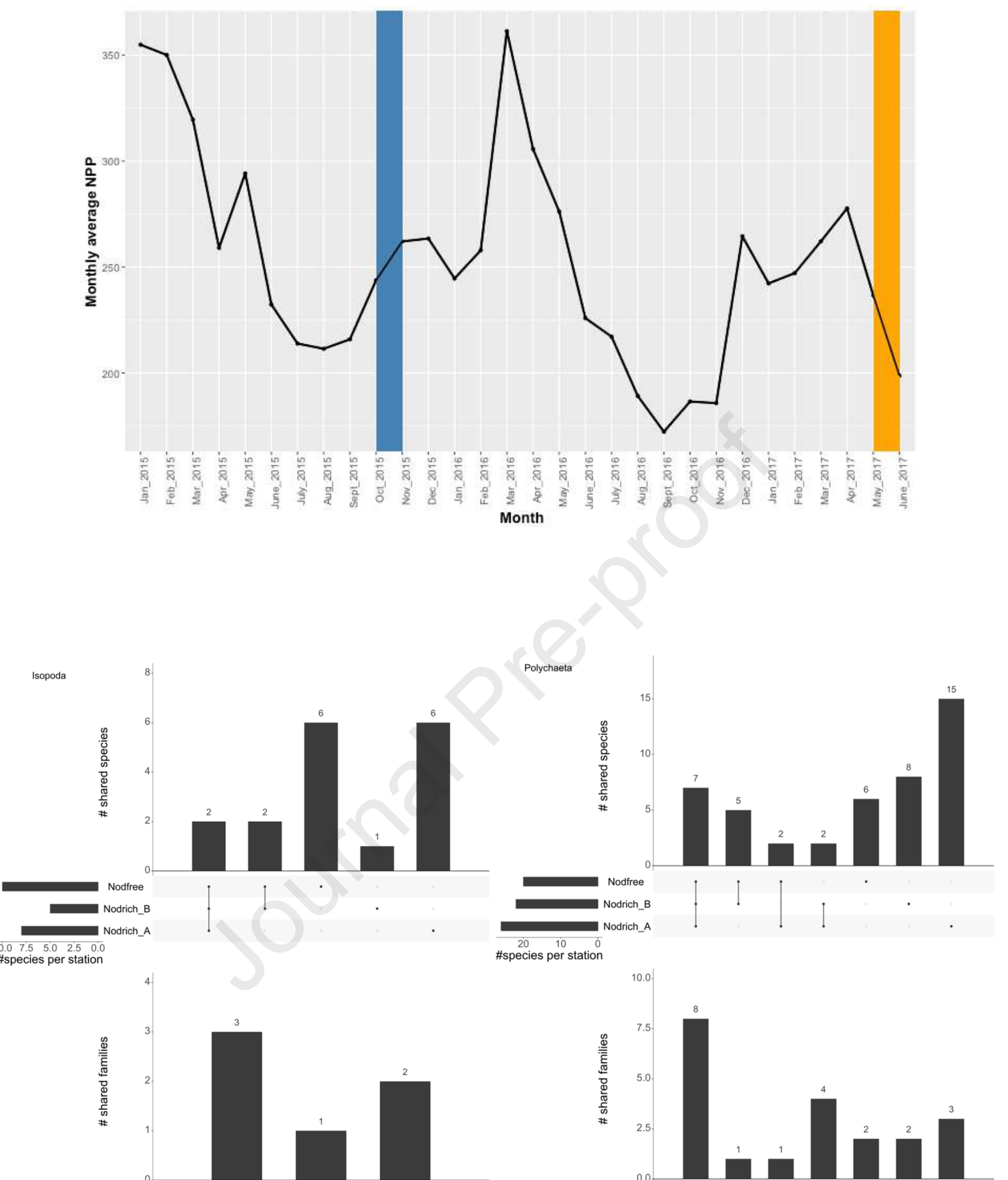

Figure 4 Upset matrix design bi-plots representing shared and unique species (upper plot) and families (lower plot) across the three stations per each of the dominant taxa (Isopoda, Polychaeta, Tanaidacea). Dots when united by a line represent the shared species/families between the different stations, for which the total number of species is reported on top of the bar. Single dots represent unique species per station. 


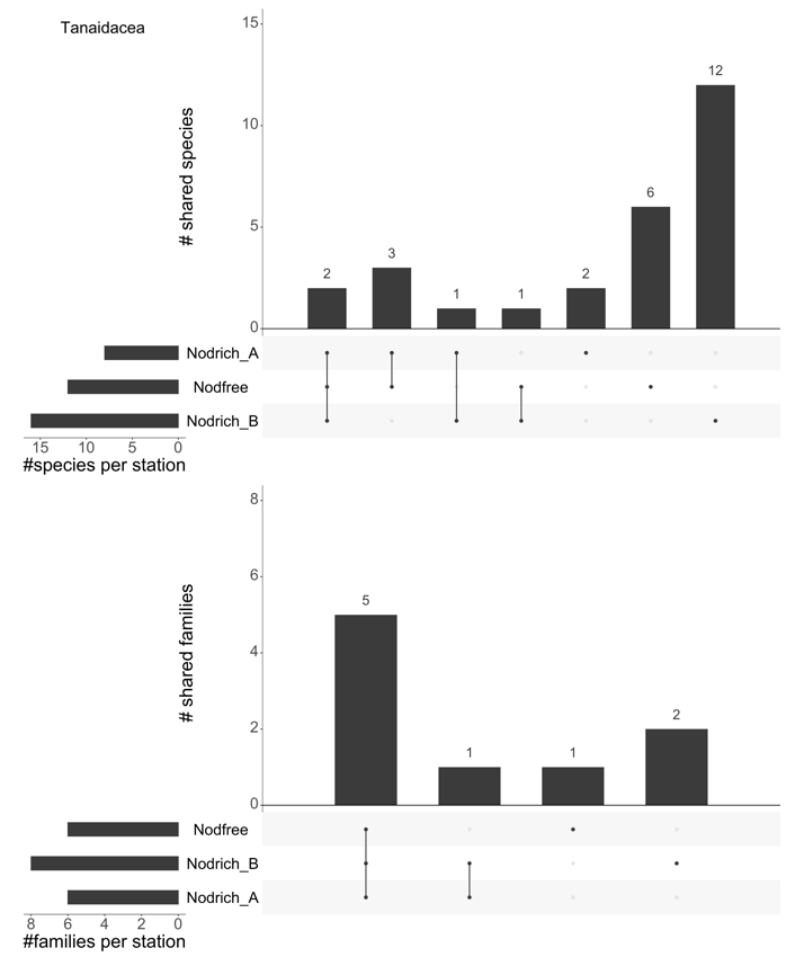

Figure 4 (continued) Upset matrix design bi-plots representing shared and unique species (upper plot) and families (lower plot) across the three stations per each of the dominant taxa (Isopoda, Polychaeta, Tanaidacea). Dots when united by a line represent the shared species/families between the different stations, for which the total number of species is reported on top of the bar. Single dots represent unique species per station. 

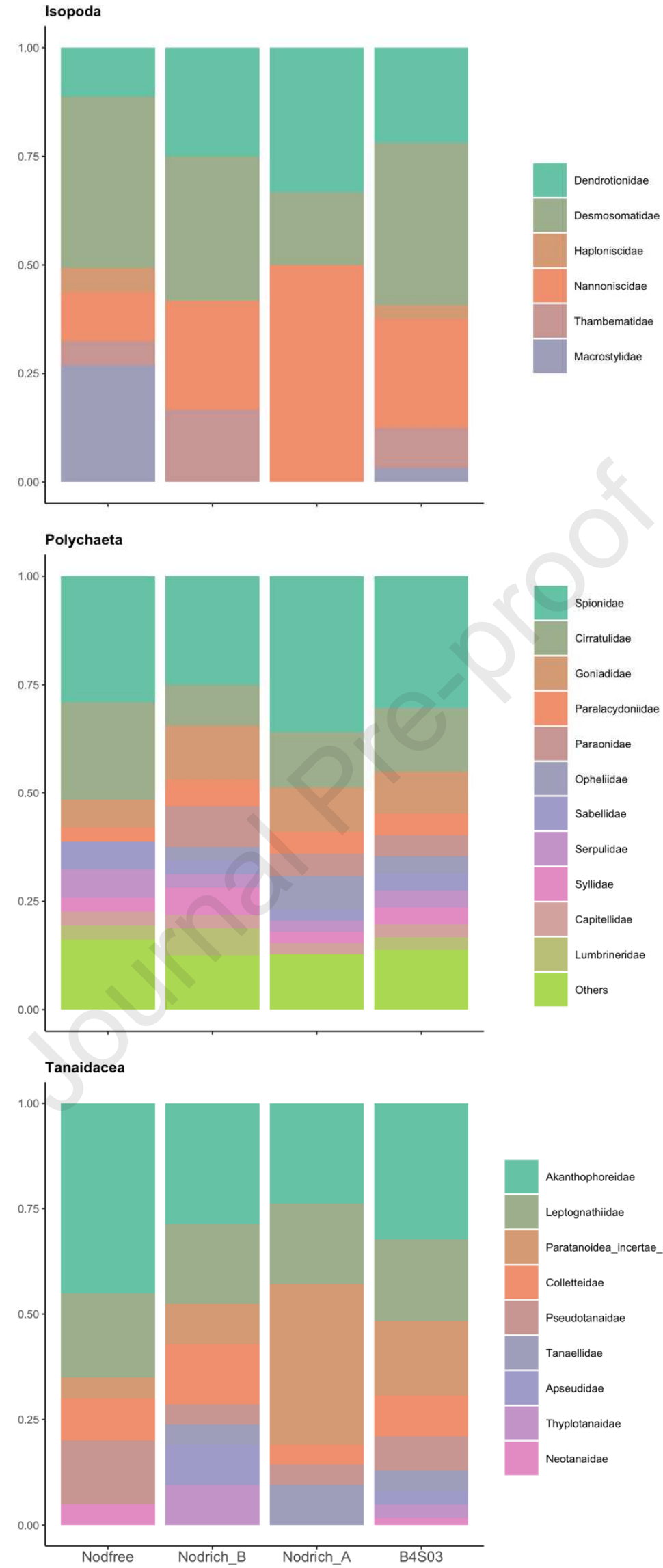

Figure 5. Family composition for the three dominant taxa (Polychaeta, Isopoda, Tanaidacea) displayed as 

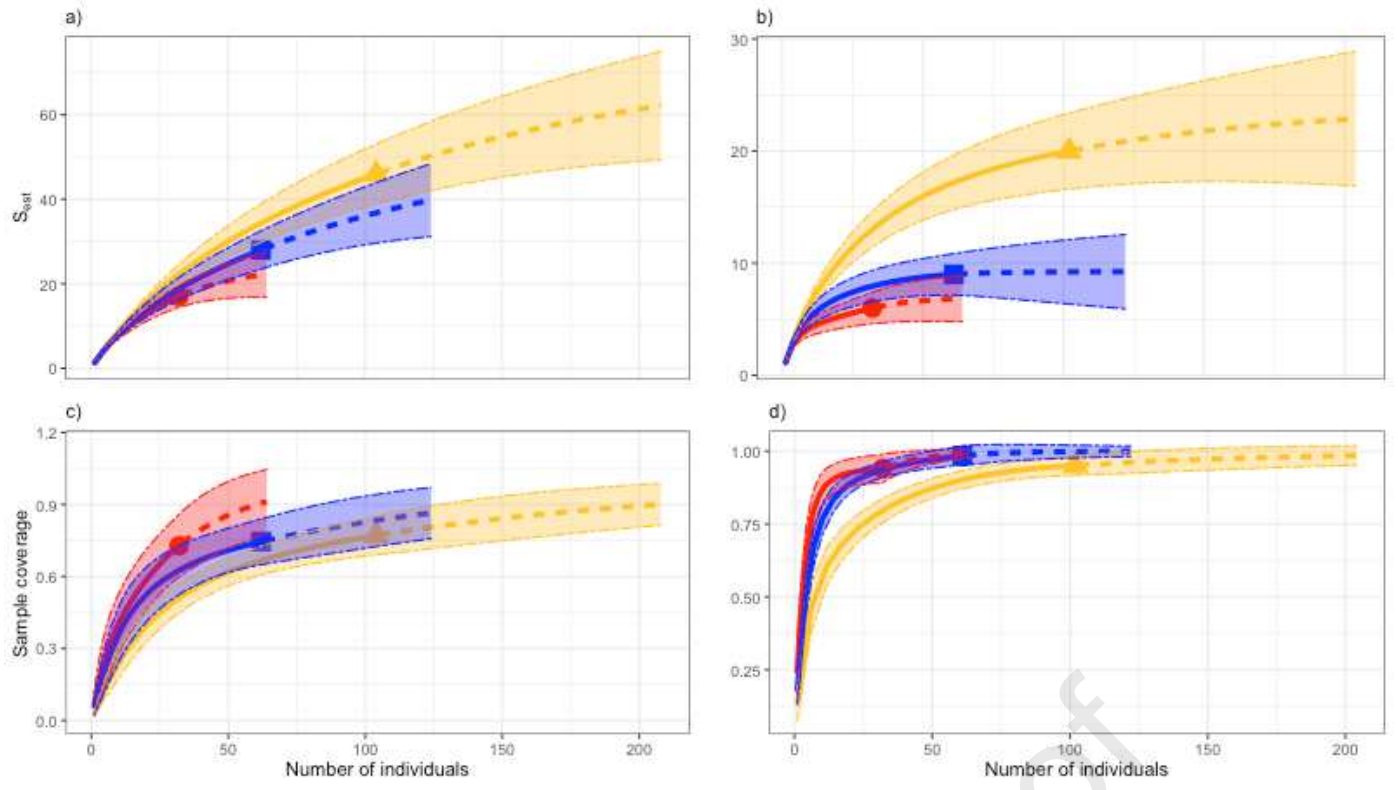

1015

Method -

Taxon $\square$ isopoda Polychata $\square$ Tanaidacea

1016 Figure 6. Sample-size-based and (a-b) coverage-based (c-d) rarefaction (solid line segment) and extrapolation (dotted line segments) sampling curves for species (species level = left side plots ; family level = right side plots) richness (Hill's number $\mathrm{q}=0$ ) with $95 \%$ confidence intervals (shaded areas) for each taxon (Isopoda in red, Polychaeta in yellow, Tanaidacea in blue) for site B4S03. 
1040 Table $1 \mathrm{a}$. Results of the multivariate/univariate two-way abiotic variables and one-way (b) biotic variables 1041 Permanova with Permdisp test results. Statistical significance is marked with a $\left.{ }^{*}\right)$, NS indicate non statistically significant results.

\begin{tabular}{|c|c|c|c|c|c|}
\hline Analysis & Parameter & Factor & dF & P-value & Permdisp \\
\hline \multicolumn{6}{|l|}{ Abiotic variables } \\
\hline \multirow[t]{3}{*}{ Multivariate Two-way Permanova } & Environmental variables (all) & Station & 2 & 0.06 . & - \\
\hline & & Layer & 1 & $0.01^{\cdot}$ & $0.003^{\star \star}$ \\
\hline & & Station*Layer & 5 & 0.11 & - \\
\hline \multirow[t]{36}{*}{ Univariate Two-way Permanova } & TOC\% & Station & 2 & NS & - \\
\hline & & Layer & 1 & $0.04^{*}$ & NS \\
\hline & & Station*Layer & 2 & NS & - \\
\hline & TN\% & Station & 2 & NS & - \\
\hline & & Layer & 1 & NS & - \\
\hline & & Station*Layer & 2 & NS & - \\
\hline & $\mathrm{TOC} / \mathrm{TN}$ & Station & 2 & NS & - \\
\hline & & Layer & 1 & 0.07 & - \\
\hline & & Station*Layer & 2 & NS & - \\
\hline & Porosity & Station & 2 & 0.0015 & NS \\
\hline & & Layer & 1 & $0.0001^{-*}$ & NS \\
\hline & & Station*Layer & 2 & NS & - \\
\hline & Median_gs & Station & 2 & NS & - \\
\hline & & Layer & 1 & NS & - \\
\hline & & Station*Layer & 2 & NS & - \\
\hline & Grain_SC & Station & 2 & $0.02^{*}$ & NS \\
\hline & & Layer & 1 & NS & - \\
\hline & & Station*Layer & 2 & 0.3 & - \\
\hline & Sand\% & Station & 2 & NS & - \\
\hline & & Layer & 1 & NS & - \\
\hline & & Station*Layer & 2 & NS & - \\
\hline & Silt\% & Station & 2 & NS & - \\
\hline & & Layer & 1 & NS & - \\
\hline & & Station*Layer & 2 & NS & - \\
\hline & Clay\% & Station & 2 & $0.039^{*}$ & $0.035^{\circ}$ \\
\hline & & Layer & 1 & NS & - \\
\hline & & Station*Layer & 2 & NS & - \\
\hline & Chl-a & Station & 2 & 0.06 . & - \\
\hline & & Layer & 4 & $0.0067^{-}$ & - \\
\hline & & Station*Layer & 8 & $0.0071^{*}$ & $0.001^{\star \star \star}$ \\
\hline & Phaeopigments & Station & 2 & $0.03^{\circ}$ & - \\
\hline & & Layer & 4 & $0.0001^{*}$ & - \\
\hline & & Station*Layer & 8 & $0.0088^{-*}$ & $0.001^{\star \star \star *}$ \\
\hline & CPE & Station & 2 & $0.03^{\circ}$ & - \\
\hline & & Layer & 4 & $0.0001^{*}$ & - \\
\hline & & Station*Layer & 8 & $0.0064^{-*}$ & $0.001^{* * \star}$ \\
\hline \multirow[t]{2}{*}{ Univariate One-way Permanova } & Nodule abundance & Station & 2 & $0.0042^{-*}$ & NS \\
\hline & Nodule coverage (\%) & Station & 2 & $0.04^{*}$ & NS \\
\hline
\end{tabular}


Table $1 \mathrm{~b}$. Results of the multivariate/univariate one-way Permanova on the biotic variables with Permdisp test results. Statistical significance is marked with a $\left(^{*}\right)$, NS indicate non statistically significant results.

\begin{tabular}{llllll} 
Analysis & Parameter & Factor dF & P-value & Permdisp \\
\hline Higher Taxon macrofauna (excl.meiofauna) & & & & & \\
\hline Univariate One-way Permanova & Total abundance & Station 2 & NS & NS \\
Multivariate One-way Permanova & Taxon composition & Station 2 & NS & NS \\
\hline ISOPODA & & & &
\end{tabular}

Higher Taxon (Family)

Univariate One-way Permanova

Diversity indices: $\quad$ Station 2

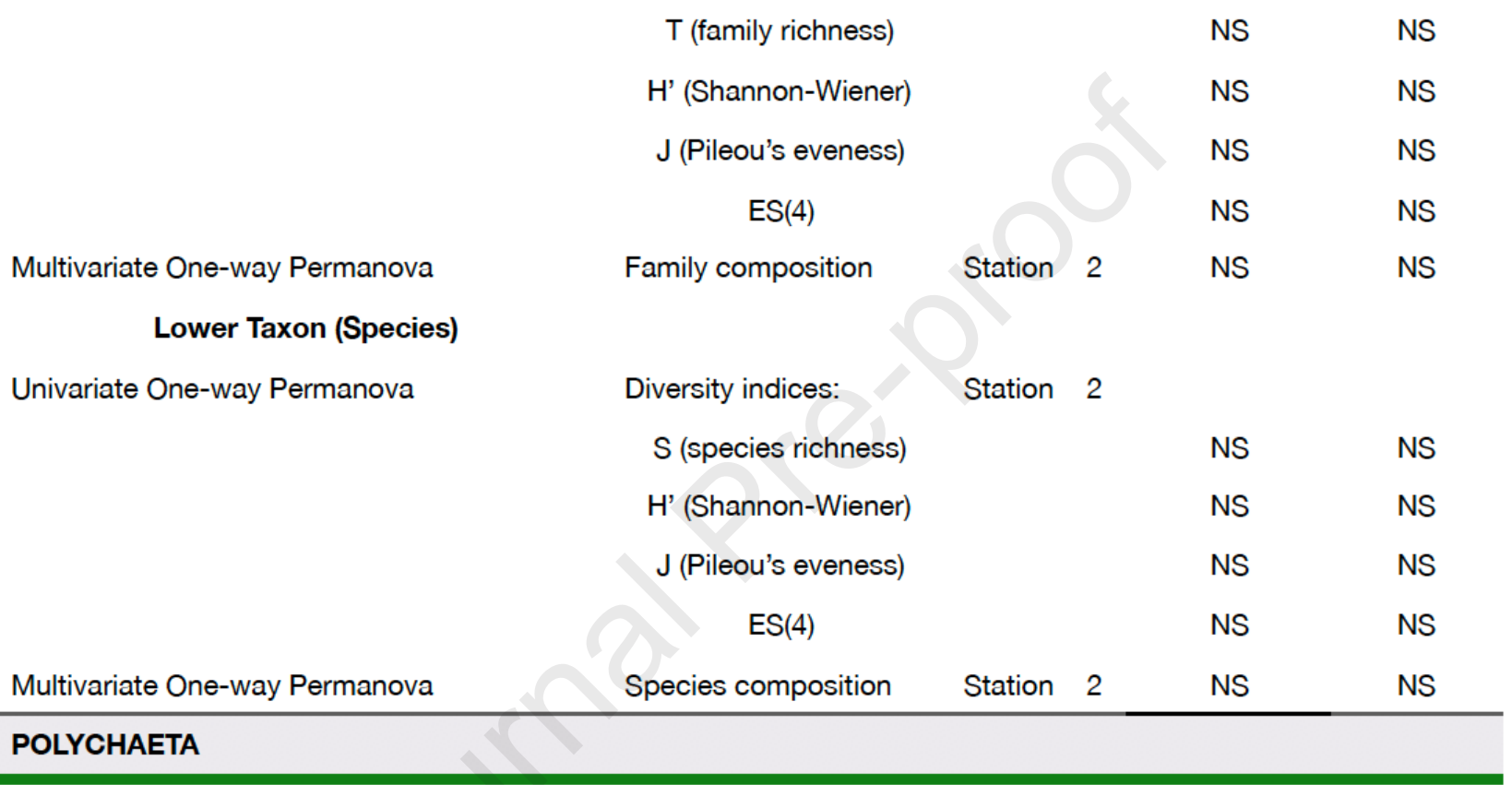

Higher Taxon (Family)

Univariate One-way Permanova

Multivariate One-way Permanova

\section{Lower Taxon (Species)}

Univariate One-way Permanova

Multivariate One-way Permanova
Diversity indices:

$\mathrm{T}$ (family richness)

H' (Shannon-Wiener)

J (Pileou's eveness)

ES(4)

Family composition

Diversity indices:

$$
\begin{aligned}
& \text { S (species richness) } \\
& \text { H' (Shannon-Wiener) } \\
& \text { J (Pileou's eveness) }
\end{aligned}
$$

ES(4)

\begin{tabular}{|c|c|c|c|}
\hline & & NS & NS \\
\hline & & NS & $0.003^{* *}$ \\
\hline & & NS & $0.001^{* \star *}$ \\
\hline & & NS & 0.004 ** \\
\hline Station & 2 & NS & NS \\
\hline Station & 2 & & \\
\hline & & NS & NS \\
\hline & & NS & 0.032 * \\
\hline & & NS & $0.001^{\star \star \star *}$ \\
\hline & & NS & $0.001^{* \star *}$ \\
\hline Station & 2 & NS & NS \\
\hline
\end{tabular}

Species composition
Station 2 
1051

1052

1053

Table $1 \mathrm{~b}$ (Continued). Results of the multivariate/univariate one-way Permanova on the biotic variables with Permdisp test results. Statistical significance is marked with a $\left(^{*}\right)$, NS indicate non statistically significant results.

\begin{tabular}{|c|c|c|c|c|c|}
\hline Analysis & Parameter & Factor & dF & P-value & Permdisp \\
\hline \multicolumn{6}{|l|}{ TANAIDACEA } \\
\hline \multicolumn{6}{|l|}{ Higher Taxon (Family) } \\
\hline \multirow[t]{5}{*}{ Univariate One-way Permanova } & Diversity indices: & Station & 2 & & \\
\hline & $\mathrm{T}$ (family richness) & & & NS & NS \\
\hline & H' (Shannon-Wiener) & & & NS & NS \\
\hline & J (Pileou's eveness) & & & 0.07 & $0.001^{* \star *}$ \\
\hline & $\mathrm{ES}(4)$ & & & NS & NS \\
\hline Multivariate One-way Permanova & Family composition & Station & 2 & NS & NS \\
\hline \multicolumn{6}{|l|}{ Lower Taxon (Species) } \\
\hline \multirow[t]{5}{*}{ Univariate One-way Permanova } & Diversity indices: & Station & 2 & & \\
\hline & $\mathrm{T}$ (species richness) & & & NS & NS \\
\hline & H' (Shannon-Wiener) & & & NS & NS \\
\hline & J (Pileou's eveness) & & & NS & $0.001^{\star \star \star}$ \\
\hline & ES(4) & & & NS & NS \\
\hline Multivariate One-way Permanova & Species composition & Station & 2 & NS & $0.001 * \star \star$ \\
\hline
\end{tabular}

Table 2. Average values \pm standard deviation of the environmental parameters: sand content (\%), silt content $(\%)$, clay content $(\%)$, porosity (\% vol), nodule abundance $(\mathrm{Kg} \mathrm{m}-2)$, Chlorphyll-a $(\mu \mathrm{g} / \mathrm{g})$, Phaeopigments $(\mu \mathrm{g} / \mathrm{g}), \mathrm{TOC}=$ total organic carbon; $\mathrm{TN}=$ total nitrogen.

\begin{tabular}{|c|c|c|c|c|c|c|c|c|c|c|c|}
\hline & \multicolumn{2}{|c|}{ Sand (\%) } & \multicolumn{2}{|c|}{ Silt (\%) } & \multicolumn{2}{|c|}{ Clay $(\%)$} & \multicolumn{2}{|c|}{ Porosity (\% vol) } & \multicolumn{2}{|c|}{ Median.gs } & \\
\hline & $0-5 \mathrm{~cm}$ & $5-10 \mathrm{~cm}$ & $0-5 \mathrm{~cm}$ & $5-10 \mathrm{~cm}$ & $0-5 \mathrm{~cm}$ & $5-10 \mathrm{~cm}$ & $0-5 \mathrm{~cm}$ & $5-10 \mathrm{~cm}$ & $0-5 \mathrm{~cm}$ & $5-10 \mathrm{~cm}$ & \\
\hline Nodrree & $9.15 \pm 0.90$ & $10.24 \pm 0.60$ & $74.38 \pm 0.44$ & $73.91 \pm 0.29$ & $16.45 \pm 0.49$ & $15.83 \pm 0.34$ & $0.893 \pm 0.008$ & $0.86 \pm 0.007$ & $16.95 \pm 0.89$ & $17.70 \pm 0.93$ & \\
\hline Nodrich_B & $9.38+2.51$ & $8.79 \pm 3.23$ & $72.87 \pm 1.64$ & $74.04 \pm 1.91$ & $17.73+1.29$ & $17.15+1.52$ & $0.89 \pm 0.005$ & $0.84 \pm 0.006$ & $16.77 \pm 2.09$ & $16.55 \pm 2.42$ & \\
\hline \multirow[t]{3}{*}{ Nodrich_A } & $9.22 \pm 0.96$ & $6.52 \pm 0.26$ & $73.63 \pm 0.99$ & $75.27 \pm 0.06$ & $17.13 \pm 0.16$ & $18.19 \pm 0.30$ & $0.88 \pm 0.007$ & $0.83 \pm 0.006$ & $17.08 \pm 0.57$ & $15.61 \pm 0.26$ & \\
\hline & \multicolumn{2}{|c|}{ Grain_sc } & \multicolumn{2}{|c|}{ Chlorphyll-a (ug/g) } & \multicolumn{2}{|c|}{ Phaeopigments ( $(\mu / g)$} & \multicolumn{2}{|c|}{ TOC $(\%)$} & \multicolumn{2}{|c|}{$\operatorname{TN}(\%)$} & Nodule abundance \\
\hline & $0-5 \mathrm{~cm}$ & $5-10 \mathrm{~cm}$ & $0-5 \mathrm{~cm}$ & $5-10 \mathrm{~cm}$ & $0-5 \mathrm{~cm}$ & $5-10 \mathrm{~cm}$ & $0-5 \mathrm{~cm}$ & $5-10 \mathrm{~cm}$ & $0-5 \mathrm{~cm}$ & $5-10 \mathrm{~cm}$ & $\mathrm{Kg} \mathrm{m-2}$ \\
\hline Nodfroo & $1.209+0.013$ & $1.210 \pm 0.014$ & $0.0012+0.0014$ & $\mathrm{MN}$ & $0.017+0.01$ & $\mathrm{NA}$ & $0.68+0.01$ & $0.52 \perp 0.03$ & $0.20 \perp 0.01$ & $0.22+0.02$ & $0.53+0.72$ \\
\hline Nodrich_B & $1.267 \pm 0.035$ & $1.221 \pm 0.035$ & $0.000 \pm 0.000$ & NA & $0.0109 \pm 0.0065$ & NA & $0.59 \pm 0.06$ & $0.53 \pm 0.11$ & $0.29 \pm 0.20$ & $0.21 \pm 0.06$ & $20.01 \pm 5.56$ \\
\hline Nodrich_A & $1.272 \pm 0.031$ & $1.248+0.013$ & $0.00038 \pm 0.00052$ & NA & $0.0073 \pm 0.0072$ & NA & $0.62 \pm 0.03$ & $0.54 \pm 0.04$ & $0.21 \pm 0.00$ & $0.19 \pm 0.01$ & $24.17 \pm 1.54$ \\
\hline
\end{tabular}

Table 3. Diversity indices of the three main taxa at the family and species level $. T=$ taxon richness (species or family); H' = Shannon Wiener diversity index; J' = Pilou's evenness index; rarefaction method of Sanders for expected species ES(4). Values are reported as average \pm standard deviation. 


\begin{tabular}{|c|c|c|c|c|}
\hline ISOPODA & $\mathrm{T}$ & $\mathrm{H}^{\prime}$ & $J^{\prime}$ & $\mathrm{ES}(4)$ \\
\hline Nodfree & $3.33 \pm 1.52$ & $1.04 \pm 0.45$ & $0.91 \pm 0.11$ & $2.35 \pm 0.56$ \\
\hline Nodrich_B & $2.25 \pm 1.25$ & $0.68 \pm 0.55$ & $0.99 \pm 0.01$ & $1.92 \pm 0.72$ \\
\hline Nodrich_A & $1.66 \pm 0.57$ & $0.44 \pm 0.38$ & $0.95 \pm 0.05$ & $1.60 \pm 0.53$ \\
\hline Nodrich B & $2.50 \pm 0.17$ & $0.73 \pm 0.63$ & $0.74 \pm 0.49$ & $1.97 \pm 0.80$ \\
\hline Nodrich_A & $2.00 \pm 0.01$ & $0.59 \pm 0.55$ & $0.66 \pm 0.57$ & $1.84 \pm 0.79$ \\
\hline POLYCHAETA & $\mathbf{T}$ & $\mathrm{H}^{\prime}$ & $J^{\prime}$ & $\mathrm{ES}(4)$ \\
\hline \multicolumn{5}{|l|}{ Family level } \\
\hline Nodrich_A & $4.0 \pm 2.52$ & $1.21 \pm 0.46$ & $0.97 \pm 0.03$ & $2.59 \pm 0.44$ \\
\hline \multicolumn{5}{|l|}{ Species level } \\
\hline Nodfree & $9.0 \pm 1.73$ & $2.15 \pm 0.17$ & $0.98 \pm 0.01$ & $3.43 \pm 0.09$ \\
\hline Nodrich_B & $6.75 \pm 4.92$ & $1.53 \pm 1.06$ & $0.73 \pm 0.48$ & $2.75 \pm 1.17$ \\
\hline Nodrich_A & $10.6 \pm 1.15$ & $2.29 \pm 0.07$ & $0.97 \pm 0.02$ & $3.48 \pm 0.06$ \\
\hline TANAIDACEA & $\mathrm{T}$ & $H^{\prime}$ & J' & $\mathrm{ES}(4)$ \\
\hline \multicolumn{5}{|l|}{ Family level } \\
\hline Nodfree & $3.33 \pm 1.15$ & $1.07 \pm 0.33$ & $0.94 \pm 0.06$ & $2.38 \pm 0.40$ \\
\hline ALL THREE TAXA (Species) & $\mathrm{T}$ & $\mathrm{H}^{\prime}$ & $J^{\prime}$ & ES(4) \\
\hline Nodfree & $18.33 \pm 2.51$ & $2.85 \pm 0.144$ & $0.32 \pm 0.01$ & $4.84 \pm 0.086$ \\
\hline Nodrich_B & $13.75 \pm 6.50$ & $2.46 \pm 0.59$ & $0.37 \pm 0.08$ & $4.88 \pm 0.09$ \\
\hline Nodrich_A & $16.66 \pm 2.08$ & $2.65 \pm 0.19$ & $0.32 \pm 0.01$ & $4.58 \pm 0.23$ \\
\hline
\end{tabular}

Table 4. B4S03 site lower-taxon (species) non-parametric diversity estimation analysis. $\mathrm{S}_{\mathrm{obs}}=$ observed species diversity; $\mathrm{S}_{\mathrm{Chao1}}=$ Chao1 asymptotic estimated diversity; $\mathrm{S}_{\mathrm{obs}} / \mathrm{S}_{\mathrm{Chao1}}=$ recorded diversity based on Chao1 estimator. The second part of the Table ("Necessary sampling effort") reports the results of the calculations 
1088

1089

based on the $\mathrm{S}_{\text {Chao1 }}$ asymptotic diversity of how many extra samples/individuals/area should be sampled to record a diversity $g=x$ (e.g. as fraction of the asymptotic estimated diversity $S_{C h a 01}$ ).

\begin{tabular}{lccc} 
& Isopoda & Polychaeta & Tanaidacea \\
\hline $\mathrm{n}^{\circ}$ samples taken & 10 & 10 & 10 \\
$\mathrm{n}^{\circ}$ of singletons & 9 & 24 & 16 \\
$\mathrm{n}^{\circ}$ of doubletons & 5 & 10 & 5 \\
$\mathrm{n}$ (individuals identified) & 31 & 104 & 62 \\
Sobs $_{\text {Schao1 (non-parametric estimator) }}$ & 17 & 46 & 28 \\
Recorded diversity (S & 25 & 74.8 & 53.6 \\
(S) & 0.68 & 0.61 & 0.52
\end{tabular}

Necessary sampling effort (Chao et al., 2014)

\begin{tabular}{|c|c|c|c|}
\hline \multicolumn{4}{|l|}{$g=1$} \\
\hline Additional individuals & 126 & 745 & 575 \\
\hline Additional samples & 41 & 72 & 93 \\
\hline Tot. samples needed & 51 & 82 & 103 \\
\hline Times original sample size & 5 & 8 & 10 \\
\hline Total area $\left(\mathrm{m}^{2}\right)$ to be samples to reach $\mathrm{g}$ & 13 & 20 & 26 \\
\hline $\mathrm{g}$ must be greater than & 0.77 & 0.77 & 0.47 \\
\hline \multicolumn{4}{|l|}{$g=0.95$} \\
\hline Additional individuals & 33 & 336 & 155 \\
\hline Additional samples & 11 & 32 & 25 \\
\hline Tot. samples needed & 21 & 42 & 35 \\
\hline Times original sample size & 2 & 4 & 4 \\
\hline Total area $\left(\mathrm{m}^{2}\right)$ to be samples to reach $\mathrm{g}$ & 5 & 11 & 9 \\
\hline \multicolumn{4}{|l|}{$g=0.80$} \\
\hline Additional individuals & 13 & 163 & 86 \\
\hline Additional samples & 4 & 16 & 14 \\
\hline Total samples needed & 14 & 26 & 24 \\
\hline Times original sample size & 1 & 3 & 2 \\
\hline Total area $\left(\mathrm{m}^{2}\right)$ to be samples to reach $\mathrm{g}$ & 4 & 6 & 6 \\
\hline
\end{tabular}

\section{Supplementary material: Figures and Tables}

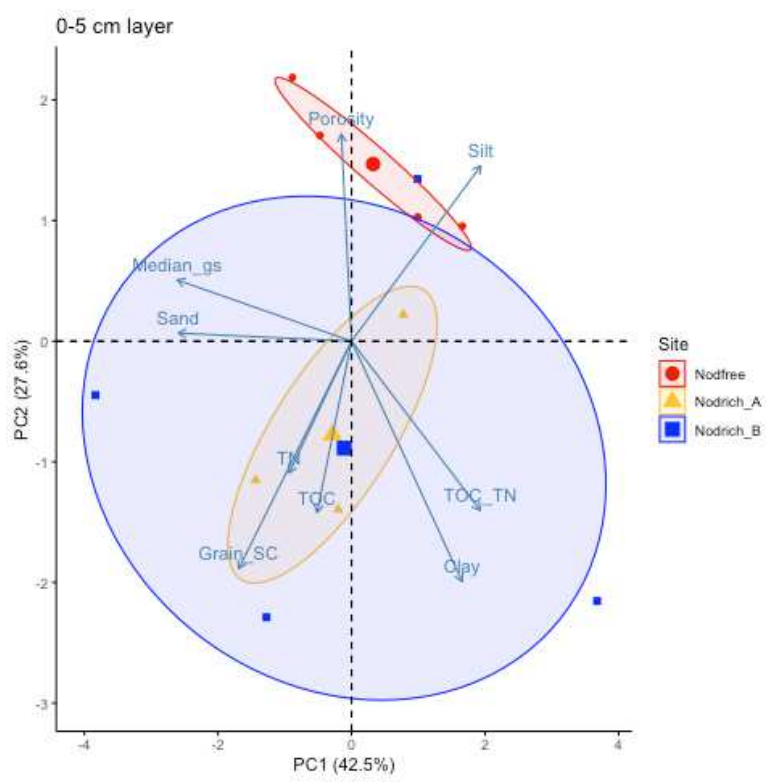

SF1. Principal component analysis (PCA) of the sediment environmental variables (excl. pigments and nodule abundance) for the $0-5 \mathrm{~cm}$ layer for the three stations (Nodfree in red, Nodrich_A in yellow, Nodrich_B in 
blue), based on Euclidean distance similarities on the normalised data. The vectors represent the environmental variables and the two axes represent the two most important principal components (PC1 and PC2) and the percentage of variability they explain is reported. The ellipses represent the 0.95 confidence interval of the data distribution of each station around a centroid.

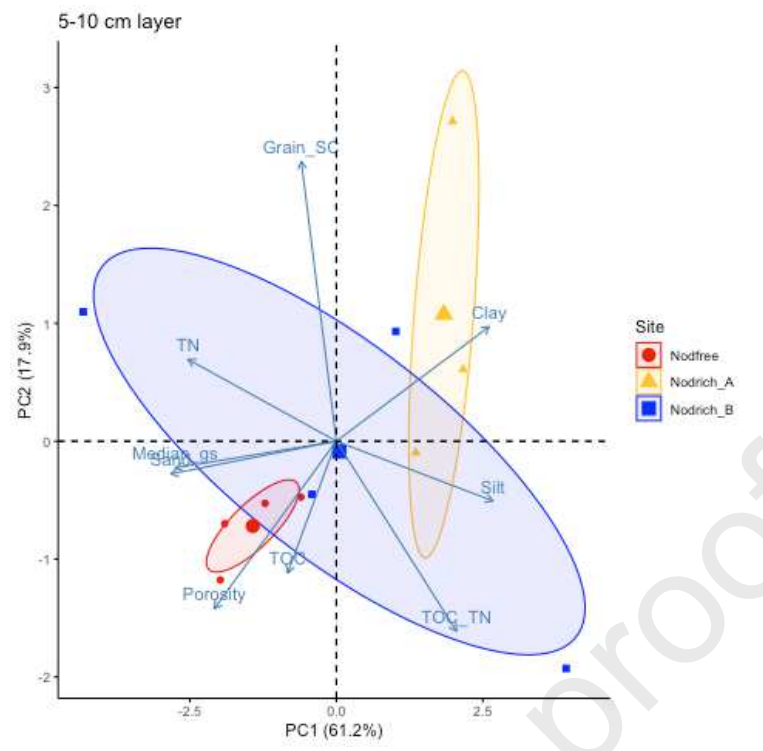

SF2. Principal component analysis (PCA) of the sediment environmental variables (excl. pigments and nodule abundance) for the $5-10 \mathrm{~cm}$ layer for the three stations (Nodfree in red, Nodrich_A in yellow, Nodrich_B in blue), based on Euclidean distance similarities on the normalised data. The vectors represent the environmental variables and the two axes represent the two most important principal components (PC1 and PC2) and the percentage of variability they explain is reported. The ellipses represent the 0.95 confidence interval of the data distribution of each station around a centroid.

Supplementary Table ST1. Details of multicorer (MUC) and boxcorer (BC) samples collected during GSRNOD17 cruise. Deployments dates are the date at which the deployment touched the floor. Coordinates are those of the MUC/BC touchdown.

\begin{tabular}{|c|c|c|c|c|c|c|c|}
\hline & SamplelD & Station ID & Date & Latitude (N) & Longitude (W) & $\begin{array}{l}\text { Deployment } \\
\text { depth }(m)\end{array}$ & Analysis \\
\hline \multicolumn{8}{|l|}{ Multicorer } \\
\hline & MUC011 & Nodfree & $26 / 05 / 2017$ & $14^{\circ} 04^{\prime} 0.088^{\prime \prime}$ & $125^{\circ} 55^{\prime} 44.437^{\prime \prime}$ & 4649 & \multirow{11}{*}{ Biogeochemistry } \\
\hline & MUC012 & Nodfree & 26/05/2017 & $14^{\circ} 03^{\prime} 33.74998^{\prime \prime}$ & $125^{\circ} 55^{\prime} 15.19011 "$ & 4575 & \\
\hline & MUC013 & Nodfree & $27 / 05 / 2017$ & $14^{\circ} 03^{\prime} 14.05729^{\prime \prime}$ & $125^{\circ} 55^{\prime} 26.86686^{\prime \prime}$ & 4573 & \\
\hline & MUC020 & Nodfree & 01/06/2017 & $14^{\circ} 02^{\prime} 59.48021^{\prime \prime}$ & $125^{\circ} 55^{\prime} 17.74194^{\prime \prime}$ & 4557 & \\
\hline & MUC014 & Nodrich_B & 28/05/2017 & $14^{\circ} 02^{\prime} 10.71719^{\prime \prime}$ & $125^{\circ} 55^{\prime} 28.34904^{\prime \prime}$ & 4537 & \\
\hline & MUC015 & Nodrich_B & 28/05/2017 & $14^{\circ} 01^{\prime} 45.23694^{\prime \prime}$ & $125^{\circ} 55^{\prime} 30.26248^{\prime \prime}$ & 4555 & \\
\hline & MUC016 & Nodrich_B & 28/05/2017 & $14^{\circ} 02^{\prime} 00.95803^{\prime \prime}$ & $125^{\circ} 55^{\prime} 44.49076^{\prime \prime}$ & 4545 & \\
\hline & MUC021 & Nodrich_B & 03/06/2017 & $14^{\circ} 02^{\prime} 08.20105^{\prime \prime}$ & $125^{\circ} 54^{\prime} 35.65350^{\prime \prime}$ & 4550 & \\
\hline & MUC017 & Nodrich_A & $30 / 05 / 2017$ & $14^{\circ} 06^{\prime} 14.91210^{\prime \prime}$ & $125^{\circ} 52^{\prime} 42.06784^{\prime \prime}$ & 4480 & \\
\hline & MUC018 & Nodrich_A & $30 / 05 / 2017$ & $14^{\circ} 06^{\prime} 43.72101^{\prime \prime}$ & $125^{\circ} 52^{\prime} 17.59307^{\prime \prime}$ & 4510 & \\
\hline & MUC019 & Nodrich_A & $30 / 05 / 2017$ & $14^{\circ} 07^{\prime} 03.34491^{\prime \prime}$ & $125^{\circ} 52^{\prime} 46.14806^{\prime \prime}$ & 4500 & \\
\hline \multicolumn{8}{|l|}{ Box-corer } \\
\hline & $\mathrm{BC} 037$ & Nodfree & $26 / 05 / 2017$ & $14^{\circ} 04^{\prime} 02.81202^{\prime \prime}$ & $125^{\circ} 55^{\prime} 44.40113^{\prime \prime}$ & 4629 & \multirow{10}{*}{$\begin{array}{l}\text { Macrofauna higher/ } \\
\text { lower taxon } \\
\text { analysis } \\
\text { Nodule abundance } \\
\text { estimation }\end{array}$} \\
\hline & $\mathrm{BC} 039$ & Nodfree & $27 / 05 / 2017$ & $14^{\circ} 03^{\prime} 32.45348^{\prime \prime}$ & $125^{\circ} 55^{\prime} 15.66124^{\prime \prime}$ & 4585 & \\
\hline & BC056 & Nodfree & $02 / 06 / 2017$ & $14^{\circ} 02^{\prime} 58.49970^{\prime \prime}$ & $125^{\circ} 55^{\prime} 19.39387^{\prime \prime}$ & 4558 & \\
\hline & $\mathrm{BC} 042$ & Nodrich_B & 28/05/2017 & $14^{\circ} 02^{\prime} 09.47831^{\prime \prime}$ & $125^{\circ} 55^{\prime} 29.03077^{\prime \prime}$ & 4552 & \\
\hline & $\mathrm{BCO} 43$ & Nodrich_B & 28/05/2017 & $14^{\circ} 02^{\prime} 01.97395^{\prime \prime}$ & $125^{\circ} 55^{\prime} 44.46696^{\prime \prime}$ & 4546 & \\
\hline & $\mathrm{BC} 045$ & Nodrich_B & $28 / 05 / 2017$ & $14^{\circ} 01^{\prime} 44.57942^{\prime \prime}$ & $125^{\circ} 55^{\prime} 31.03251^{\prime \prime}$ & 4554 & \\
\hline & $\mathrm{BC} 057$ & Nodrich_B & 03/06/2017 & $14^{\circ} 02^{\prime} 08.90255^{\prime \prime}$ & $125^{\circ} 54^{\prime} 35.57861^{\prime \prime}$ & 4509 & \\
\hline & $\mathrm{BC} 050$ & Nodrich_A & $29 / 05 / 2017$ & $14^{\circ} 06^{\prime} 16.67737^{\prime \prime}$ & $125^{\circ} 52^{\prime} 41.48177^{\prime \prime}$ & 4481 & \\
\hline & $\mathrm{BC} 053$ & Nodrich_A & $30 / 05 / 2017$ & $14^{\circ} 10^{\prime} 16.59182^{\prime \prime}$ & $125^{\circ} 55^{\prime} 01.98463^{\prime \prime}$ & 4588 & \\
\hline & $\mathrm{BC} 054$ & Nodrich_A & $31 / 05 / 2017$ & $14^{\circ} 07^{\prime} 04.34218^{\prime \prime}$ & $125^{\circ} 52^{\prime} 45.41828^{\prime \prime}$ & 4502 & \\
\hline
\end{tabular}


1114 ST2. Higher-taxon densities expressed as individuals $\mathrm{m}^{-2}$ for macrofauna and meiofauna (total counts multi1115 plied by a factor 4) per each box-core per station during GSRNOD17.

1116

\begin{tabular}{|c|c|c|c|c|c|c|c|c|c|c|}
\hline & \multicolumn{3}{|c|}{ Nodfree } & \multicolumn{4}{|c|}{ Nodrich_B } & \multicolumn{3}{|c|}{ Nodrich_A } \\
\hline & $\mathrm{BC} 037$ & BC039 & BC056 & BC042 & $\mathrm{BC} 043$ & $\mathrm{BC} 045$ & $\mathrm{BC} 057$ & BC052 & BC054 & $\mathrm{BC} 050$ \\
\hline \multicolumn{11}{|l|}{ Macrofauna Taxa } \\
\hline Amphipoda & 0 & 0 & 4 & 4 & 0 & 36 & 12 & 4 & 16 & 0 \\
\hline Bivalvia & 4 & 8 & 8 & 0 & 4 & 8 & 12 & 8 & 12 & 4 \\
\hline Chaetognata & 0 & 0 & 0 & 0 & 0 & 4 & 0 & 4 & 0 & 0 \\
\hline Gastropoda & 0 & 0 & 0 & 0 & 0 & 4 & 0 & 0 & 4 & 0 \\
\hline Isopoda & 48 & 28 & 20 & 12 & 12 & 8 & 28 & 16 & 8 & 12 \\
\hline Oligochaeta & 0 & 0 & 0 & 0 & 0 & 0 & 0 & 4 & 0 & 0 \\
\hline Ophiuroidea & 0 & 4 & 0 & 0 & 4 & 0 & 0 & 0 & 0 & 0 \\
\hline Polychaeta & 60 & 88 & 132 & 128 & 20 & 60 & 96 & 128 & 96 & 116 \\
\hline Scaphopoda & 0 & 0 & 0 & 0 & 0 & 0 & 4 & 0 & 0 & 0 \\
\hline Tanaidacea & 20 & 44 & 40 & 48 & 8 & 16 & 28 & 4 & 60 & 12 \\
\hline \multirow[t]{2}{*}{ Unknown } & 8 & 4 & 8 & 0 & 16 & 16 & 0 & 4 & 16 & 8 \\
\hline & 0 & 0 & 0 & 0 & 0 & 0 & 0 & 0 & 0 & 0 \\
\hline Total abundance & 140 & 176 & 212 & 192 & 64 & 152 & 180 & 172 & 212 & 152 \\
\hline \multicolumn{11}{|l|}{ Meiofauna Taxa } \\
\hline Copepoda & 60 & 100 & 144 & 64 & 12 & 28 & 72 & 80 & 56 & 36 \\
\hline Nematoda & 4 & 44 & 72 & 48 & 0 & 12 & 32 & 28 & 32 & 8 \\
\hline Ostracoda & 0 & 20 & 16 & 24 & 0 & 20 & 32 & 12 & 32 & 8 \\
\hline Foraminifera & 0 & 0 & 4 & 4 & 0 & 0 & 8 & 0 & 0 & 4 \\
\hline Euphasiacea & 0 & 0 & 0 & 0 & 4 & 0 & 0 & 0 & 0 & 0 \\
\hline Total abundance & 64 & 164 & 236 & 140 & 16 & 60 & 144 & 120 & 120 & 56 \\
\hline
\end{tabular}

ST3 a Permdisp analysis results and pair-wise tests for abiotic variables. 


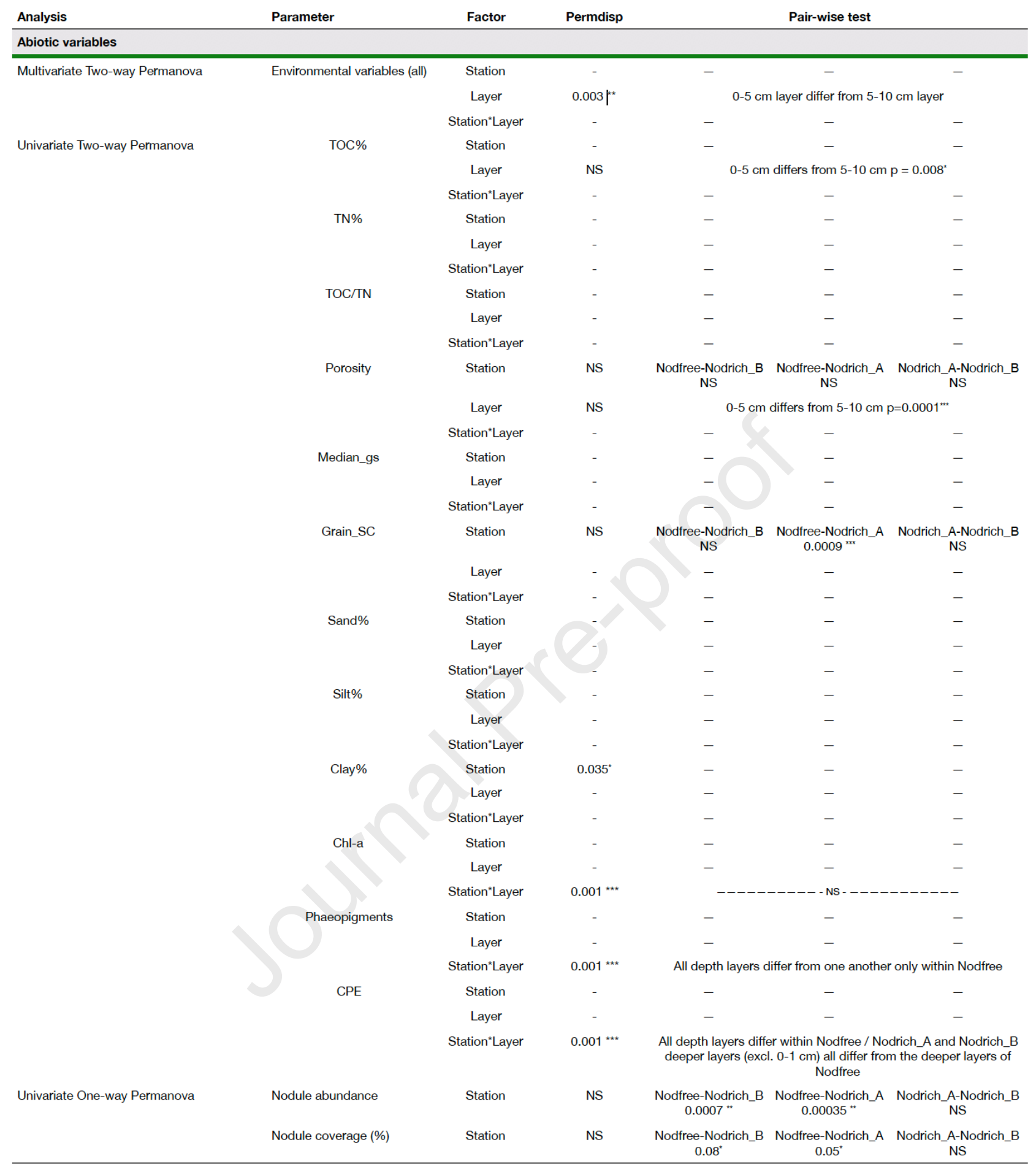




\begin{tabular}{llllll} 
Analysis & Parameter & Factor & Permdisp & Pair-wise test \\
\hline Higher Taxon macrofauna (excl.meiofauna) & & & & & \\
\hline Univariate One-way Permanova & Total abundance & Station & NS & - & - \\
Multivariate One-way Permanova & Taxon composition & Station & NS & - & - \\
\hline ISOPODA & & & & - \\
\hline
\end{tabular}

Higher Taxon (Family)

Univariate One-way Permanova

Diversity indices: Station

$T$ (family richness) NS

H' (Shannon-Wiener)

$\mathrm{J}$ (Pileou's eveness)

$\mathrm{ES}(4)$

Multivariate One-way Permanova

Family composition

Lower Taxon (Species)

Univariate One-way Permanova

Diversity indices:

NS

$\mathrm{S}$ (species richness)

H' (Shannon-Wiener)

J (Pileou's eveness)

ES(4)

Multivariate One-way Permanova

Species composition

Station

POLYCHAETA

Higher Taxon (Family)

Univariate One-way Permanova

Diversity indices: Station

$T$ (family richness)

H' (Shannon-Wiener)

$\mathrm{J}$ (Pileou's eveness)

ES(4)

Multivariate One-way Permanova

Lower Taxon (Species)

Univariate One-way Permanova

Family composition

Diversity indices:

Station

$\mathrm{S}$ (species richness)

H' (Shannon-Wiener)

$\mathrm{J}$ (Pileou's eveness)

ES(4)

Species composition

Multivariate One-way Permanova

Station NS

TANAIDACEA
Higher Taxon (Family)

Univariate One-way Permanova

Diversity indices:

Station

$\mathrm{T}$ (family richness)

H' (Shannon-Wiener)

$\mathrm{J}$ (Pileou's eveness)

$\mathrm{ES}(4)$

Multivariate One-way Permanova

Family composition

Lower Taxon (Species)

Univariate One-way Permanova

Station

$\mathrm{T}$ (species richness)

H' (Shannon-Wiener)

$\mathrm{J}$ (Pileou's eveness)

ES(4)

Species composition

Station

NS
NS
$0.001^{\star * \star}$
NS
NS

NS -

ST4. List of shared (between two or three sites) and unique (per station) species/morphospecies per each of the three main taxa. The $\left(^{*}\right)$ indicate that the species/morphospecies is a singleton (encountered only once 
across samples). The "\#number" refers to the specimen identifier. The specification (cf) means that the identification was done on a difficult to identify specimen (e.g. badly preserved or damaged).

\begin{tabular}{|c|c|c|c|c|c|}
\hline \multirow[b]{2}{*}{ TAXON } & \multicolumn{2}{|c|}{ Shared species } & \multicolumn{3}{|c|}{ Unique species } \\
\hline & Between all three sites & Between two sites & Nodfree & Nodrich_B & Nodrich_A \\
\hline \multicolumn{6}{|l|}{ ISOPODA } \\
\hline & Dendrotion species $A$ & Chelator species B & Austroniscus species (") & Desmosomatinae species $\left({ }^{*}\right)$ & Nannoniscus species A (*) \\
\hline & Thambema species A & & Chelator species A & Nannoniscus species $C\left(^{*}\right)$ & Nannoniscus species B (*) \\
\hline & & & Eugerdella species A & & Nannoniscus species C \\
\hline & & & Haploniscus species A (*) & & Panetela species B \\
\hline & & & Macrostylis metallicola ( $\left.{ }^{*}\right)$ & & Prochelator species A \\
\hline & & & Mirabilicoxa species (*) & & Whoia species $A\left({ }^{*}\right)$ \\
\hline \multicolumn{6}{|c|}{ POLYCHAETA } \\
\hline & Aphelochaeta species \#1461 & Anguillosyllis species \#1992 & Aphelochaeta species \#1784 & Ammotrypanella species $\left({ }^{*}\right)$ & Serpulidae species \#1693 (*) \\
\hline & Aphelochaeta species \#1644 & Capitellidae species \#1821 & Chaetozone species \#1950 & Pseudoscalibregma $(c f)\left(^{*}\right)$ & Anguillosyllis species \#1990 $\left({ }^{*}\right)$ \\
\hline & Aurospio dibranchiata \#1457 & Ceratocephale (cf) abyssorum & Lacydonia species \#1412 & Goniadidae species $\left({ }^{*}\right)$ & Aphelochaeta species \#1644( $\left(^{*}\right)$ \\
\hline & Aurospio dibranchiata \#249 & Laonice species & Polaruchakov species (*) & Maldanidae species \#1915 $\left(^{*}\right)$ & Aricidea species \#1911 (*) \\
\hline & Bathyglycinde (cf) & Lumbrinerides laubieri \#2107 & Prionospio species \#1426 (*) & Paradoneis species \#1819 $\left(^{*}\right)$ & Capitellidae species \#1718 $\left({ }^{*}\right)$ \\
\hline & Paralacydonia paradoxa & Sabellidae species \#1428 & Serpulidae species \#1429 & Parexogone species (*) & Dorvilleidae species (*) \\
\hline & Prionospio species $\# 268$ & Sabellidae species \#1756 & & Poeciolochaetidae species $\left({ }^{*}\right)$ & Eulalia species $(*)$ \\
\hline & & & & Pseudomystides species $\left({ }^{*}\right)$ & Glycera species $\left({ }^{*}\right)$ \\
\hline & & & & Serpulidae species \#1455 (*) & Maldanidae species \#1742(*) \\
\hline & & & & & Octomagelona species $\left({ }^{*}\right)$ \\
\hline & & & & & Opheliidae species \#1755 (*) \\
\hline & & & & & Ophelina species \#1706 \\
\hline & & & & & Paradoneis species \#1737 (*) \\
\hline & & & & & Prionospio species \#1735 \\
\hline & & & & & Progoniada (cf) species (*) \\
\hline \multicolumn{6}{|c|}{ TANAIDACEA } \\
\hline & Forcipatia species \#6 & Arthrura species $\# 153$ & Neotanais species \#161 (*) & Leptognathia species $\left({ }^{*}\right)$ & Collettea longisetosa $\left({ }^{*}\right)$ \\
\hline & Stenotanais species $\# 59$ & Caudalonga species \#74 & New genus 4 species \#162(*) & Leptognathiella occidentalis $\left(^{*}\right)$ & Tanabnormia species \#25 (*) \\
\hline & & Insociabilitanais species $\# 160$ & Parakanthophoreus species \#63 (*) & Leptognathioides species \#18 (") & \\
\hline & & Pseudotanais species \#158 & Parakanthophoreus species \#95 & Leviapseudes species \#165 (*) & \\
\hline & & Tumidochelia species $\# 157$ & Pseudotanais geralti & Leviapseudes species \#166 (*) & \\
\hline & & & Stenotanais species $\# 55$ & New genus 1 species $\# 152\left(^{*}\right)$ & \\
\hline & & & & New genus 2 species $\# 151(*)$ & \\
\hline & & & & New genus 3 species $\# 156\left({ }^{*}\right)$ & \\
\hline & & & & New genus 5 species \#20 (*) & \\
\hline & & & & Parakanthophoreus species \#16A & \\
\hline & & & & Portarathrum species \#155 & \\
\hline & & & & Pseudotanais species \#159(*) & \\
\hline & & & & Stenotanais (cf.) species \#164(*) & \\
\hline
\end{tabular}




\begin{tabular}{|c|c|c|c|c|}
\hline & Nodfree & Nodrich_B & Nodrich_A & $\mathrm{B} 4 \mathrm{~S} 03$ \\
\hline \multicolumn{5}{|l|}{ Isopoda } \\
\hline Dendrotionidae & 0.11 & 0.25 & 0.33 & 0.22 \\
\hline Desmosomatidae & 0.39 & 0.33 & 0.17 & 0.38 \\
\hline Haploniscidae & 0.06 & 0.00 & 0.00 & 0.03 \\
\hline Nannoniscidae & 0.11 & 0.25 & 0.50 & 0.25 \\
\hline Thambematidae & 0.06 & 0.17 & 0.00 & 0.09 \\
\hline Macrostylidae & 0.27 & 0.00 & 0.00 & 0.03 \\
\hline \multicolumn{5}{|l|}{ Polychaeta } \\
\hline Spionidae & 0.29 & 0.25 & 0.36 & 0.30 \\
\hline Cirratulidae & 0.23 & 0.09 & 0.13 & 0.15 \\
\hline Goniadidae & 0.06 & 0.13 & 0.10 & 0.10 \\
\hline Paralacydoniidae & 0.03 & 0.06 & 0.05 & 0.05 \\
\hline Paraonidae & 0.00 & 0.09 & 0.05 & 0.05 \\
\hline Opheliidae & 0.00 & 0.03 & 0.08 & 0.04 \\
\hline Sabellidae & 0.06 & 0.03 & 0.03 & 0.04 \\
\hline Serpulidae & 0.06 & 0.03 & 0.03 & 0.04 \\
\hline Syllidae & 0.03 & 0.06 & 0.03 & 0.04 \\
\hline Capitellidae & 0.03 & 0.03 & 0.03 & 0.03 \\
\hline Lumbrineridae & 0.03 & 0.06 & 0.00 & 0.03 \\
\hline Nereididae & 0.06 & 0.00 & 0.03 & 0.03 \\
\hline Lacydoniidae & 0.06 & 0.00 & 0.00 & 0.02 \\
\hline Maldanidae & 0.00 & 0.03 & 0.03 & 0.02 \\
\hline Phyllodocidae & 0.00 & 0.03 & 0.03 & 0.02 \\
\hline Dorvilleidae & 0.00 & 0.00 & 0.03 & 0.01 \\
\hline Magelonidae & 0.00 & 0.00 & 0.03 & 0.01 \\
\hline Poeciolochaetidae & 0.00 & 0.03 & 0.00 & 0.01 \\
\hline Polynoidae & 0.03 & 0.00 & 0.00 & 0.01 \\
\hline Scalibregmatidae & 0.00 & 0.03 & 0.00 & 0.01 \\
\hline \multicolumn{5}{|l|}{ Tanaidacea } \\
\hline Akanthophoreidae & 0.45 & 0.29 & 0.24 & 0.32 \\
\hline Leptognathiidae & 0.20 & 0.19 & 0.19 & 0.19 \\
\hline Paratanoidea_incertae_sedis & 0.05 & 0.10 & 0.38 & 0.18 \\
\hline Colletteidae & 0.10 & 0.14 & 0.05 & 0.10 \\
\hline Pseudotanaidae & 0.15 & 0.05 & 0.05 & 0.08 \\
\hline Tanaellidae & 0.00 & 0.05 & 0.10 & 0.05 \\
\hline Apseudidae & 0.00 & 0.10 & 0.00 & 0.03 \\
\hline Thyplotanaidae & 0.00 & 0.10 & 0.00 & 0.03 \\
\hline Neotanaidae & 0.05 & 0.00 & 0.00 & 0.02 \\
\hline
\end{tabular}




\section{Highlights}

- GSR B4S03 nodule-rich and nodule-free stations are characterized by similar sedimentary parameters (sediment grain size, pigment content, TOC\%)

- GSR B4S03 macrofauna of nodule-rich stations displayed comparable densities and higher-taxon diversity to that of nodule-free sediments

- For the dominant taxa (Polychaeta, Isopoda, Tanaidacea) the current sampling effort was insufficient to characterize the GSR B4S03 site diversity at morphospecies level but covered $>90 \%$ of the diversity at the family level

- The high number of singletons, the patchiness and low densities of the dominant taxa may point to under-sampling bias with the risk to underestimate species diversity and overestimate endemism 


\section{Declaration of interests}

$\bigotimes$ The authors declare that they have no known competing financial interests or personal relationships that could have appeared to influence the work reported in this paper.

$\square$ The authors declare the following financial interests/personal relationships which may be considered as potential competing interests: 